Recibido 05 de Enero, 2019 - Aceptado 05 de Febrero, 2019

\title{
Incidencia del juego de la rayuela en el desarrollo de la psicomotricidad
}

\section{Incidence of the hopscotch game within the psychomotricity development}

\author{
Lenin Mendieta, ${ }^{1}$ Jacinto Calderón, ${ }^{1}$ Milena Valverde, ${ }^{2}$ Jennifer Vargas ${ }^{3}$
}

\section{RESUMEN}

La psicomotricidad es la disciplina que estudia el movimiento del sujeto y su relación con el desarrollo cognitivo, el objetivo del estudio fue determinar la incidencia de la práctica del juego de la rayuela en el desarrollo de la psicomotricidad en niños de 4 a 5 años. Fue un estudio controlado aleatorizado, en donde luego de seleccionar por criterios de inclusión y exclusión en niños del Jardín Parvulitos de Minerva, 12 niños fueron del grupo control y 12 del grupo entreno, tuvo una duración de 12 semanas, se valoró mediante una ficha de observación, diseñada según los objetivos del ministerio de educación del Ecuador para el ámbito de expresión corporal y motricidad para ese grupo etario con parámetros de: Adquirido, En proceso e Iniciado. Los resultados en las diferentes pruebas permitieron concluir que existe incidencia en la psicomotricidad, con la aplicación del juego de la rayuela.

Palabras clave: juego de la rayuela, psicomotricidad, esquema corporal, lateralidad, equilibrio

\section{ABSTRACT}

Psychomotricity is the discipline that studies the movement of the subject and its relationship with cognitive development, this study was aimed to determine the incidence of the practice of hopscotch in the development of psychomotor skills in children between the ages from 4 to 5 . It was a randomized controlled study, where 24 children of the 'Parvulitos de Minerva Kindergarten' were selected, considering both inclusion and exclusion criteria; as follows: 12 children were from the control group and 12 from the training group. The study lasted 12 weeks, and were assessed using an Observation form, designed according to the objectives of the Ministry of Education of Ecuador for corporal and motor expression field for that age group with parameters of: Acquired, In process and Initiated. The results in the different tests concluded that there is an incidence in psychomotor skills, with the application of the game of hopscotch.

Key Word: hopscotch game, psychomotricity, body scheme, laterality, balance.

1. Docente de la Universidad de Guayaquil, Email: lenin.mendietat@ug.edu.ec

1. Docente de la Universidad de Guayaquil, Email: jacinto.calderonv@ug.edu.ec

2. Estudiante de la Universidad de Guayaquil, Email: 1.1 secvalverdeochoa@gmail.com

3. Email: jennifervargas29@hotmail.com 


\section{INTRODUCCIÒN}

La psicomotricidad tiene su origen en el siglo XIX, cuando se empiezan a estudiar los trastornos motores y su relación con las conductas del comportamiento humano en el plano cognitivo y motriz. Wernicke, Dupré, Sherrington, determinaron la relación entre los trastornos mentales y físicos, al igual que ellos, Jean Piaget, ha aportado decisivamente a través de la psicología evolutiva del niño, en el ámbito motriz e intelectual del niño (Mendieta, Vargas, \& Mendieta, 2017).

La psicomotricidad es la disciplina que se encarga del estudio del desarrollo cognitivo y motriz del niño. Mendieta, Vargas, \& Mendieta (2017) entienden la psicomotricidad como:

Es una tarea educativa, se basa en la concepción integral del niño, concepción que, a su vez, es vista desde la interacción entre el conocimiento del objeto, la percepción de las emociones y las funciones motrices las cuales permiten el mejor desarrollo de los niños, capacidad de moverse de forma espontánea, expresarse sin dificultad y relacionarse en el contexto social desde una construcción multidimensional de respeto hacia su propio cuerpo y el de los demás (p. 46).

La psicomotricidad es algo más que el estudio del movimiento en el niño y la relación de esta con el desarrollo motor y cognitivo, es además, la disciplina que estudia de forma holística el comportamiento del niño, es la disciplina que estudia el espacio en donde transitan y se encuentran las emociones de los infantes, el desarrollo de las habilidades y destrezas motrices que le van a servir de anclaje para el aprendizaje de nuevas formas de movimiento, comunicación e interrelación social, es la disciplina desde donde se enseña el respeto y aceptación de su cuerpo y el de los demás.

El esquema corporal según coinciden (Le Boulch, 1997; Lapierre, Llorca, \& Sánchez, 2015), se constituye en uno de los elementos de base en la psicomotricidad, es la identidad de la propia ima- gen desde una percepción integral de parte del ser humano, quien se constituye como un todo y las actividades que este realiza son de igual forma vista desde la conciencia del propio yo. Para la construcción del esquema corporal, es preciso que las nociones temporo-espaciales sean adquiridas en el niño, en el infante no existen ni un espacio único ni un orden temporal que encierren el acto y el objeto de forma discriminada y consciente en un continente global (Piaget \& Inhelder, 2007).

Conforme pasan los años, el niño va adoptando nociones de orientación que coadyuban a su normal funcionamiento en el entorno donde este se desenvuelve, la relación espacio-tiempo es requisito sine qua non para el posterior desarrollo de otras nociones, el niño debe aprender dentro de la noción espacio, dónde está él en relación a los otros y el entorno, además, debe aprender la noción tiempo y la relación con el espacio. Existen otras nociones como dentro-fuera, lejos-cerca, arriba-abajo, las cuales se desarrollan a través de los juegos motores.

La lateralidad es otra de las propiedades que el niño desarrollará en la construcción de su esquema corporal, es el predominio funcional de uno de los lados del cuerpo sobre el otro, es lo que denominamos ser diestro o ambidiestro, se empieza a desarrollar a partir de los 2 años y se consolida alrededor de los 5 años, es de suma importancia a la hora del aprendizaje de la lectoescritura y el lenguaje, es indispensable la toma de conciencia de la lateralidad por parte de los niños, ya que, de esta forma, proyectará su lateralidad al exterior y tendrá ubicación temporo-espacial y ubicación sujeto-objeto (Mendieta, Vargas, \& Mendieta, 2017).

En la motricidad del sujeto recién nacido, los juegos resultan ser manifestaciones espontaneas que permiten la consolidación de los esquemas sensoriales, además, desarrollan la capacidad de simbolización e integración en grupos cooperativos, lo cual se verá reflejado en los años siguientes del infante en la consolidación de la persona- 
lidad. Elkonin, \& Uribes. (1980) manifiestan que "el juego es una forma peculiar de la actividad infantil" (p.11). Así, todo ser humano luego de los cuatro primeros años, juega mediante una acción libre, espontánea, desarrollando esta actividad en limites temporoespaciales muy definidos y siguiendo un objetivo intrínseco en ellos, que es la diversión y el disfrute del juego.

El juego es el conjunto de acciones que sirven para divertirse, que ha existido siempre en todas las culturas y en todas las circunstancias, además, se juega en todas las edades, no es característica particular del infante. En cuanto a la pedagogía como ciencia que transmite el conocimiento, hasta hace algunos años, no veía bien al juego dentro del proceso de interaprendizaje, en cambio hoy, el juego es considerado fundamental en el desarrollo de las personas como construcción individual y social, así también, el juego estimula el desarrollo físico-motor, interacción social a través de la adquisición de valores, actitudes y normas que resultan necesarias para la armonía social (Cañizares \& Carbonero, 2017).

El juego en la etapa preescolar es de suma importancia en el desarrollo del niño, como componente lúdico produce placer en quien lo practica, en el ámbito del desarrollo motor, genera beneficios en el plano cognitivo, motriz, emocional y social, así en lo cognitivo facilita que el niño sea más observador, analítico y que pueda resolver problemas; estimula la atención y concentración y tiene carácter retroalimentador; en lo motriz desarrolla las capacidades perceptivomotrices, las habilidades y destrezas motrices básicas (caminar, correr, saltar, escalar, trepar, reptar, lanzar y agarrar) y contribuye al desarrollo armónico del sujeto; en lo emocional, estimula el afianzamiento de la personalidad y equilibrio emocional, logrando además que el niño gane en autoconfianza, facilita la creatividad y lo simbólico pasa a ser real-imaginario mientras juegan, lo cual reduce situaciones de estrés, proporciona alegría y placer; en lo social es factor coadyuvante de los procesos de socialización a través de la enseñanza del respeto hacia los demás y el respe- to a las reglas establecidas en los juegos (Mendieta, Vargas, \& Mendieta, 2017).

El niño es capaz de realizar un sinfín de actividades desde el juego, tomando al movimiento como base de la enseñanza motor-perceptivocognitivo y las capacidades de pensar para actuar, es el juego una de las mejores oportunidades para mejorar factores cognoscitivos tales como: preparación, estar alerta; atención, concentración; recepción, percepción; reconocimiento de patrones, relaciones y contrastes; selectividad, discriminación; comprensión, traducción, interpretación, extrapolación; análisis; generación de soluciones alternativas; síntesis; toma de decisiones; planeación motriz o praxia; seguir secuencias; memoria, almacenamiento de datos; traducir de un modo a otro; aplicación apropiada de la información; transferencia del aprendizaje; $y$, evaluación.

El juego sirve, además, para el desarrollo de las relaciones lógico-matemáticas (Torbert, 1982). El juego en el currículo ecuatoriano de la educación inicial, está imbricado de tal forma que permite en los estudiantes la experimentación de diferentes prácticas que contribuyen al desarrollo de esas habilidades y destrezas que ya se mencionaron, así como también, ayuda a la percepción de su cuerpo y el de los demás, el dominio y disponibilidad corporal y motora desde los distintos juegos, la comunicación (ideas y mensajes que expliciten sus estados de ánimo, sensaciones, emociones y percepciones) mediante la construcción de su propia narrativa y por supuesto los valores (Mineduc. 2017).

Los juegos tradicionales son aquellos que pasan de generación en generación, son aquellos que ha perdurado en el tiempo y a pesar de sufrir ligeros cambios, mantienen la esencia y el objetivo inicial, son juegos que no fueron escritos, ni llevan una guía específica, ni tampoco fueron diseñados para educar, sino que nacieron para hacer divertirse a quienes lo practicaban y se quedaron. Los juegos populares y tradicionales en Ecuador, forman parte de nuestra cultura, en estás formas 
lúdicas se destaca el legado histórico-cultural de los pueblos que llega a convertirse en una tradición representativa de cada lugar (Ortega \& Gallegos, 2016).

La rayuela es un juego de conocimiento de uno mismo, consiste en lanzar un objeto pequeño de forma plana sobre una serie de cuadrados (o círculos u otra forma) numerados, dibujados en el suelo para luego ir saltando sobre los números a buscar el objeto, también, se puede empujar con la punta del zapato el objeto. Es un juego tan antiguo que hasta ha servido para creación literaria en la cual se indica en forma retórica y romántica la manera de jugar (Cortázar, 1963; Blanes, 2005). Así también, se trata al juego de la rayuela para el aprendizaje de las artes visuales, como agente traductor del lenguaje gráfico e imágenes provocadas por disparadores verbales, utilizando los colores como expresión de fantasía e imaginación (Palopoli, 2006).

En el desarrollo de la rayuela se comienza tirando una piedra, ficha o teja en unas celdas (cuadrados) que tiene una secuencia numérica, se intenta que la piedra caiga dentro del cuadrado sin tocar las líneas que delimitan los cuadros, se recorre la rayuela en un solo pie, salvo que toque asentar los dos pies (depende de las reglas de cada región ya que la rayuela es un juego internacional), se pasan las celdas saltándolas sin perder el equilibrio, las celda 4 y 5 están juntas, allí se asientan los pies (uno en cada celda), se pasa luego en un solo pie hasta la celda 7 y 8 que están juntas y se asientan los dos pies como en la 4 y 5 , se vuelve al número 1 saltando y dándose la vuelta para regresar haciendo los mismos saltos, la piedra puede ser empujada con la punta del zapato o recogida con las manos (depende de las reglas).

Se continua el juego hasta que la piedra haya pasado por todas las celdas, cuando la piedra toca línea o se sale de la celda, se pierde el turno y habrá que esperar otra ronda. Quién completa la secuencia primero, gana el juego (Joaquín \& $\mathrm{Ne}$ ciosup, 2017).
El objetivo del estudio fue determinar la incidencia del juego de la rayuela en el desarrollo psicomotor de niños de 4 a 5 años de edad

\section{MÉTODOS Y MATERIALES}

Fue un estudio experimental mediante una prueba controlada aleatorizada (White, Sabarwal , \& de Hoop, 2014), para determinar la incidencia del juego de la rayuela en el desarrollo psicomotor, se trabajó con 24 niños (15 niñas y 9 niños) de entre 4 a 5 años, de la escuela jardín Parvulitos de Minerva, divididos aleatoriamente en dos grupos: control (G0) y entreno (G1), doce niños en cada grupo, el estudio tuvo una duración de 12 semanas con una frecuencia de tres días a la semana (lunes, miércoles y viernes), cada sesión con una duración de 30 minutos, con intervalo de una ronda de juegos y descanso al terminar cada ronda, la misma que tenía una duración aproximada de 7-8 minutos y el descanso de 2-3 minutos entre rondas.

Se obtuvo el consentimiento informado por escrito de los padres de familia de los infantes, luego de invitarles a conocer el estudio para permitir que sus hijos participen en el mismo; se explicó en qué consistía la investigación, se indicaron los objetivos y métodos; así también, la duración; los posibles beneficios y la inexistencia de riesgos o molestias que pudiesen afectar a los niños; se informó que se mantendría la confidencialidad de los archivos con la identidad de los participantes; se asumió la responsabilidad de hacer atender a los participantes por un médico si estando en la práctica el niño se lesiona durante la práctica; se informó que los niños pueden retirarse del estudio si así lo deciden ellos o sus padres.

Se tomaron en cuenta criterios de inclusión y exclusión tales como: tener entre 4 años cumplidos y 5 años nueve meses; al empezar el estudio; estar en buen estado de salud para lo cual se realizó la prescripción médica del ejercicio; deseos de participar del estudio y firma del consentimiento informado por escrito. Los criterios de exclusión 
son los antagónicos a los de inclusión.

El estudio contó con la parte práctica del juego de la rayuela, como base del mismo, en el cual se trabajaron las habilidades y destrezas motrices básicas de caminar, correr, saltar, lanzar y agarrar, fuerza, resistencia, equilibrio; nociones temporo espaciales, lateralidad; relaciones lógico-matemáticas; coordinación óculo-manual y; comunicación mediante la interacción social.

El G0 no participó en las sesiones del juego de la rayuela, sin embargo, realizó las actividades diarias de su grado, El G1 realizó el juego de la rayuela, todos los estudiantes de este grupo asistieron en un $100 \%$ a las sesiones de juego y par- ticiparon activamente de las actividades lúdicas, las prácticas fueron realizadas en los patios del Complejo Norte de la Universidad de Guayaquil, previamente los estudiantes de la carrera de educadores de párvulos, del segundo semestre 20181 de la asignatura de psicomotricidad I, diseñaron, dibujaron y pintaron rayuelas con diferentes formas, para lograr diferentes objetivos.

Se realizaron pruebas pre y pos estudio en donde se evaluó mediante un test para la valoración con una ficha de observación, utilizando la escala de: Adquirido (A), Progreso adecuado (PA), En proceso (EP). Los criterios de evaluación fueron tomados del texto de educación inicial (Mineduc,

\section{RESULTADOS}

Tabla No ${ }^{\circ}$. Coordinación dinámica global en sus diferentes formas de locomoción para desplazarse con seguridad

\begin{tabular}{|c|c|c|c|c|c|c|c|c|c|c|c|c|}
\hline \multirow{4}{*}{$\begin{array}{c}\begin{array}{c}\text { Momentos de la } \\
\text { evaluación }\end{array} \\
\text { Grupos } \\
\text { Criterios }\end{array}$} & \multicolumn{12}{|c|}{ Escala de valoración } \\
\hline & \multicolumn{4}{|c|}{$\mathbf{A}^{*}$} & \multicolumn{4}{|c|}{ EP* } & \multicolumn{4}{|c|}{$\mathbf{I}^{*}$} \\
\hline & \multicolumn{2}{|c|}{ Pre } & \multicolumn{2}{|c|}{ Pos } & \multicolumn{2}{|c|}{ Pre } & \multicolumn{2}{|c|}{ Pos } & \multicolumn{2}{|c|}{ Pre } & \multicolumn{2}{|c|}{ Pos } \\
\hline & G0 & G1 & G0 & G1 & G0 & G1 & G0 & G1 & G0 & G1 & G0 & G1 \\
\hline $\begin{array}{l}\text { Camina y corre con } \\
\text { soltura y seguridad } \\
\text { manteniendo el } \\
\text { equilibrio a diferentes } \\
\text { distancias, } \\
\text { orientaciones y ritmos } \\
\text { en espacios parciales; }\end{array}$ & 66,7 & 66,7 & 75 & 100 & 33,3 & 25 & 25 & 0 & 0 & 8,3 & 0 & 0 \\
\hline $\begin{array}{l}\text { Camina, corre y salta } \\
\text { de un lugar a otro } \\
\text { coordinadamente } \\
\text { combinando estas } \\
\text { formas de } \\
\text { desplazamiento, a } \\
\text { velocidades } \\
\text { diferentes. }\end{array}$ & 58,3 & 58,3 & 66,7 & 100 & 25 & 25 & 25 & 0 & 16,7 & 16,7 & 8,3 & 0 \\
\hline $\begin{array}{c}\text { Salta en dos pies en } \\
\text { sentido vertical } 20 \text { a } \\
30 \mathrm{~cm} \text { en altura y en } \\
\text { sentido horizontal } \\
\text { longitudes de } \\
\text { aproximadamente } 50 \\
\text { a } 70 \mathrm{~cm} \text {; Salta de un } \\
\text { pie a otro } \\
\text { alternadamente, de } \\
\text { manera autónoma }\end{array}$ & 50 & 50 & 53 & 100 & 16,7 & 16,7 & 25 & 0 & 33,3 & 33,3 & 16,7 & 0 \\
\hline
\end{tabular}


Gráfico $\mathrm{N}^{\circ} 1$ Camina y corre con soltura y seguridad manteniendo el equilibrio a diferentes distancias, orientaciones y ritmos en espacios parciales

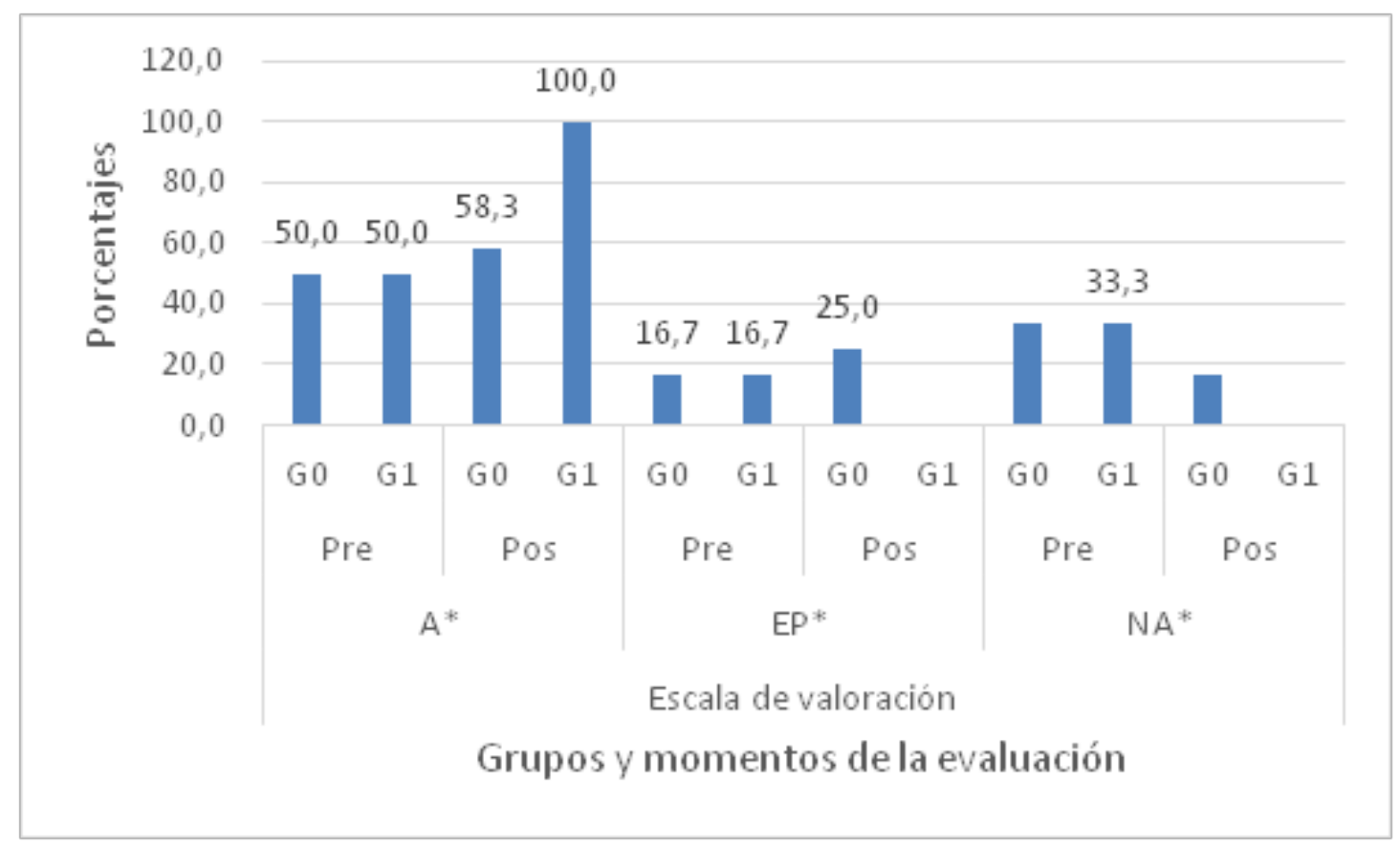

Gráfico No2. Camina, corre y salta de un lugar a otro coordinadamente combinando estas formas de desplazamiento, a velocidades diferentes.

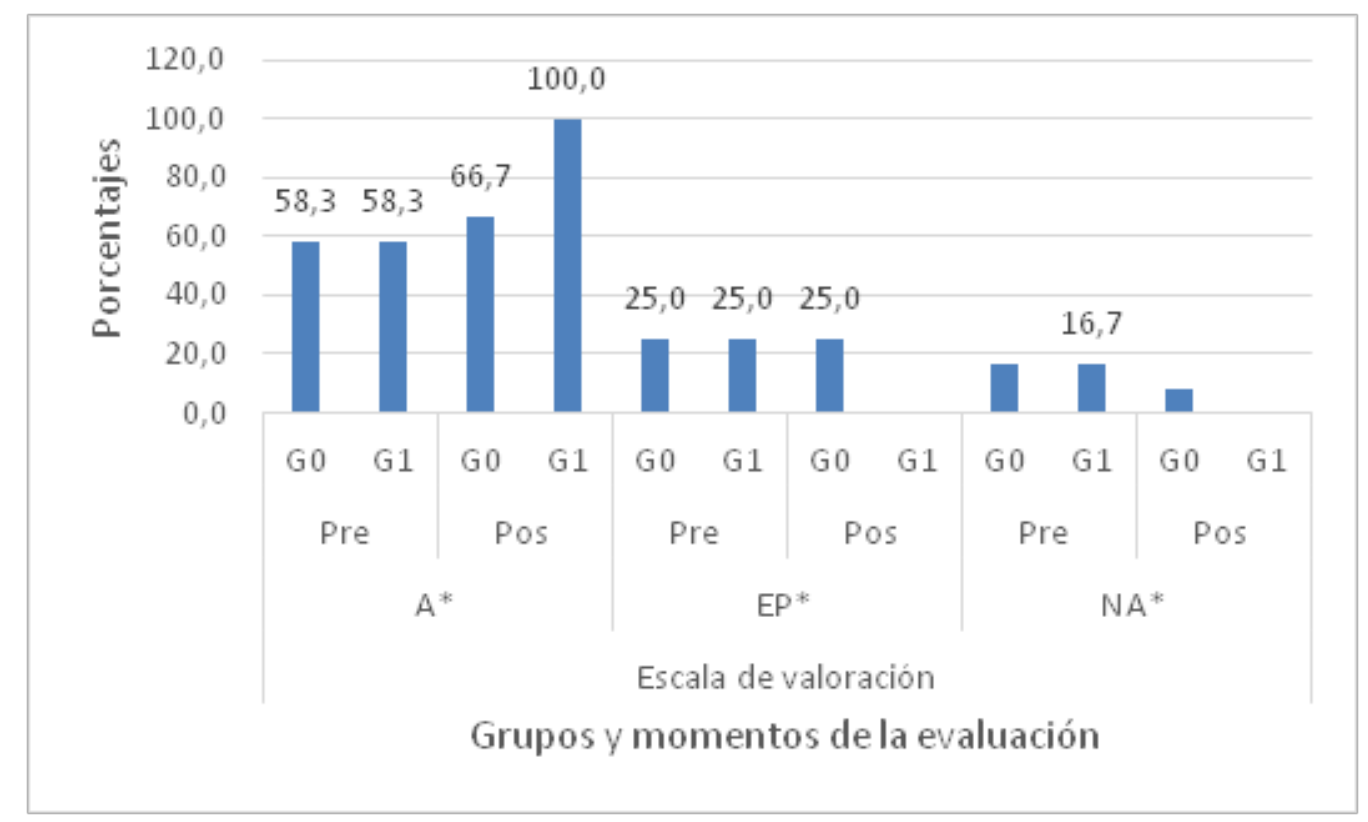


Gráfico No3. Salta en dos pies en sentido vertical 20 a $30 \mathrm{~cm}$ en altura y en sentido horizontal longitudes de aproximadamente 50 a $70 \mathrm{~cm}$; Salta de un pie a otro alternadamente, de manera autónoma

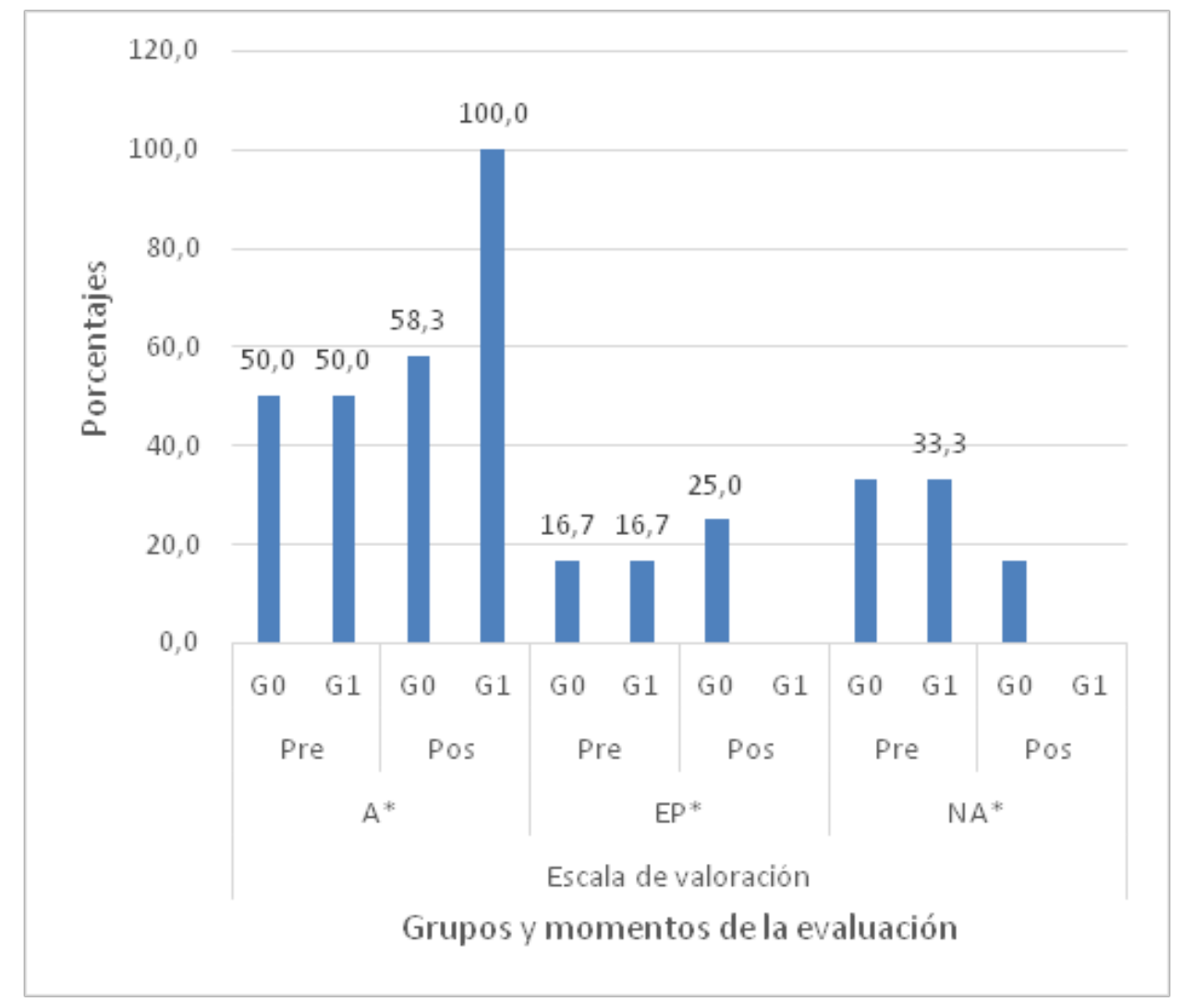

Tabla No2. Control de la fuerza y tono muscular en la ejecución de actividades que le permitan la realización de movimientos coordinados

\begin{tabular}{|c|c|c|c|c|c|c|c|c|c|c|c|c|}
\hline \multirow{4}{*}{$\begin{array}{c}\text { Momentos de la evaluación } \\
\text { Grupos } \\
\text { Criterios }\end{array}$} & \multicolumn{12}{|c|}{ Escala de valoración } \\
\hline & \multicolumn{4}{|c|}{$A^{*}$} & \multicolumn{4}{|c|}{ EP* } & \multicolumn{4}{|c|}{$I^{*}$} \\
\hline & \multicolumn{2}{|c|}{ Pre } & \multicolumn{2}{|c|}{ Pos } & \multicolumn{2}{|c|}{ Pre } & \multicolumn{2}{|c|}{ Pos } & \multicolumn{2}{|c|}{ Pre } & \multicolumn{2}{|c|}{ Pos } \\
\hline & G0 & G1 & G0 & G1 & G0 & G1 & G0 & G1 & G0 & G1 & G0 & G1 \\
\hline $\begin{array}{c}\text { Ejecuta actividades } \\
\text { coordinadamente y con un } \\
\text { control adecuado de fuerza y } \\
\text { tonicidad muscular como lanzar } \\
\text { y agarrar objetos. }\end{array}$ & 60 & 60 & 66 & 100 & 30 & 25 & 25 & 0 & 10 & 15 & 8,3 & 0 \\
\hline $\mathrm{A}=$ Adquirido & FP & $-\mathrm{F}$ & $\mathrm{rror}$ & 0 & $\mathrm{J \Delta} \cdot$ & N & $d g$ & & & & & \\
\hline
\end{tabular}


Gráfico No4. Ejecuta actividades coordinadamente y con un control adecuado de fuerza y tonicidad muscular como lanzar y agarrar objetos.

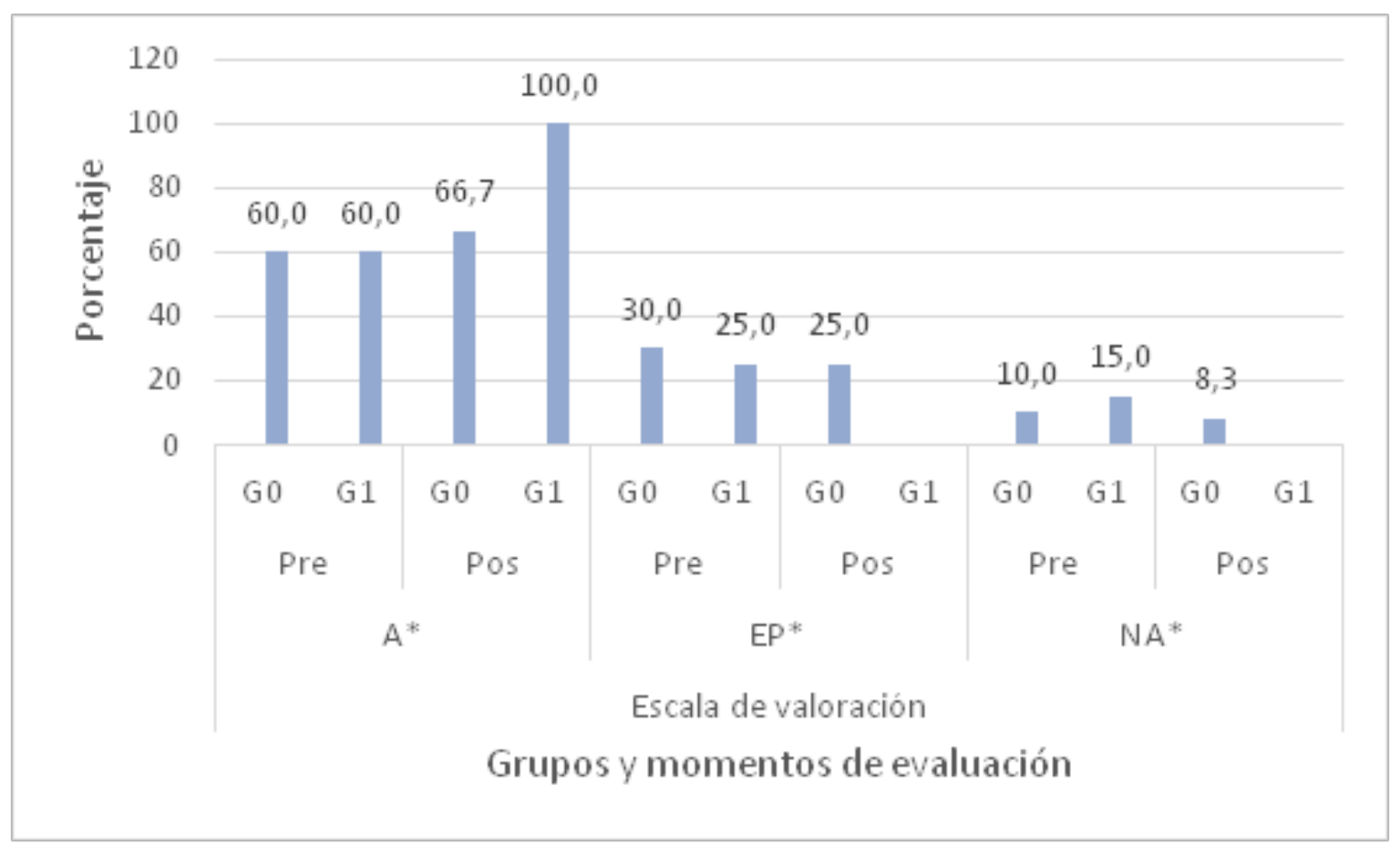

Tabla No3. Desarrollo del control postural en actividades de equilibrio estático y dinámico afianzando el dominio de los movimientos de su cuerpo

\begin{tabular}{|c|c|c|c|c|c|c|c|c|c|c|c|c|}
\hline \multirow{4}{*}{$\begin{array}{c}\text { Momentos de la } \\
\text { evaluación } \\
\text { Grupos } \\
\text { Criterios }\end{array}$} & \multicolumn{12}{|c|}{ Escala de valoración } \\
\hline & \multicolumn{4}{|c|}{$\mathbf{A}^{*}$} & \multicolumn{4}{|c|}{$\mathbf{E P}^{*}$} & \multicolumn{4}{|c|}{ I* $^{*}$} \\
\hline & \multicolumn{2}{|c|}{ Pre } & \multicolumn{2}{|c|}{ Pos } & \multicolumn{2}{|c|}{ Pre } & \multicolumn{2}{|c|}{ Pos } & \multicolumn{2}{|c|}{ Pre } & \multicolumn{2}{|c|}{ Pos } \\
\hline & G0 & G1 & G0 & G1 & G0 & G1 & G0 & G1 & G0 & G1 & G0 & G1 \\
\hline $\begin{array}{c}\text { Realiza ejercicios } \\
\text { de equilibrio } \\
\text { estático y } \\
\text { dinámico, } \\
\text { controlando los } \\
\text { movimientos de } \\
\text { las partes gruesas } \\
\text { del cuerpo }\end{array}$ & 58,3 & 58,3 & 66,7 & 100 & 25 & 25 & 25 & 0 & 16,7 & 16,7 & 8,3 & 0 \\
\hline $\begin{array}{c}\text { Mantiene el } \\
\text { equilibro al } \\
\text { caminar sobre } \\
\text { líneas rectas, } \\
\text { curvas y } \\
\text { quebradas con } \\
\text { altura (aprox. } 20 \\
\text { cm) logrando un } \\
\text { adecuado control } \\
\text { postural }\end{array}$ & 60 & 60 & 66,7 & 100 & 30 & 25 & 25 & 0 & 10 & 15 & 8,3 & 0 \\
\hline $\begin{array}{c}\text { Mantiene un } \\
\text { adecuado control } \\
\text { postural en } \\
\text { diferentes } \\
\text { posiciones del } \\
\text { cuerpo y en } \\
\text { desplazamientos }\end{array}$ & 50 & 50 & 58,3 & 75,0 & 16,7 & 16,7 & 25 & 25 & 33,3 & 33,3 & 16,7 & 0 \\
\hline
\end{tabular}


Gráfico No5. Realiza ejercicios de equilibrio estático y dinámico, controlando los movimientos de las partes gruesas del cuerpo.

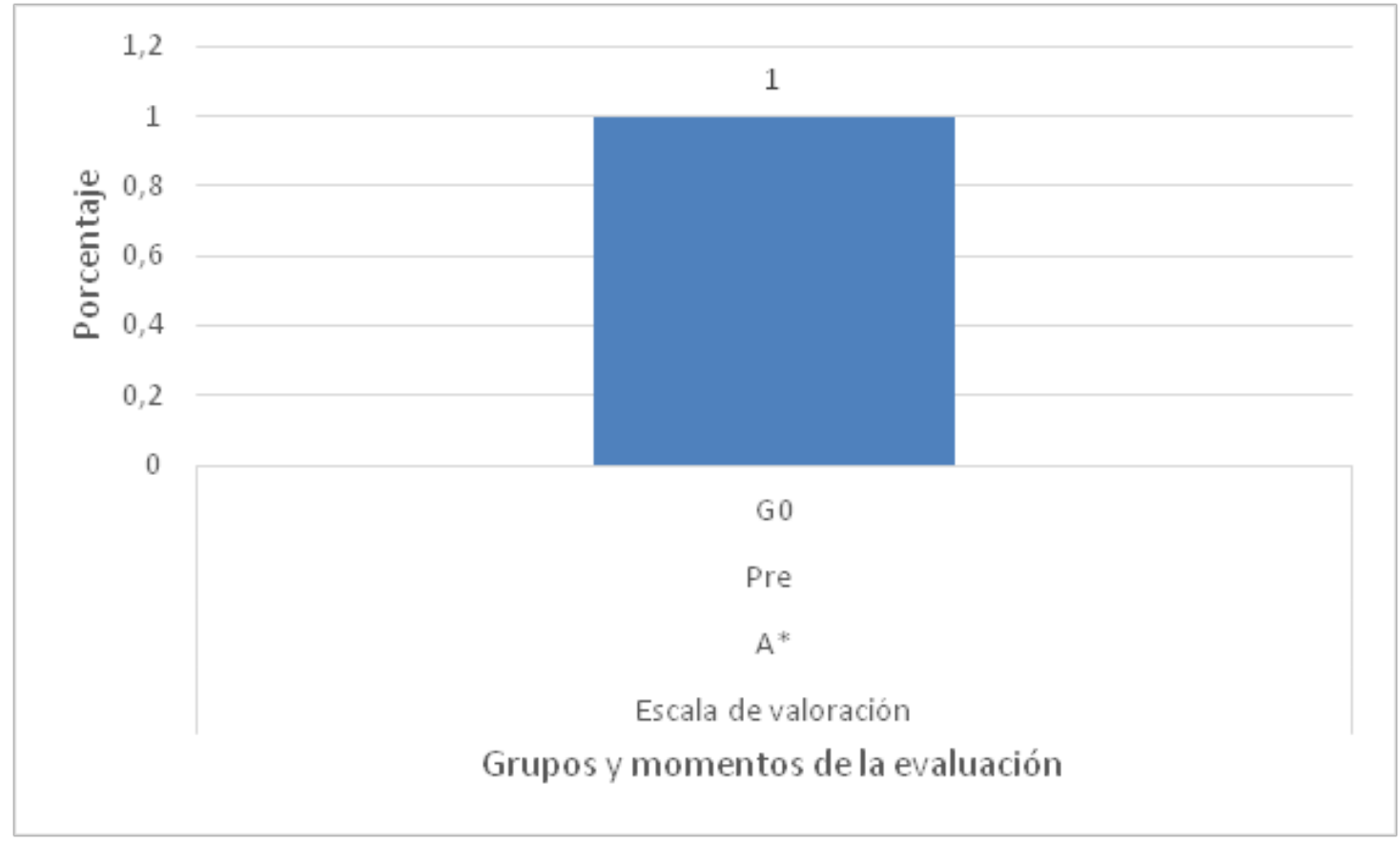

Gráfico No6. Mantiene el equilibro al caminar sobre líneas rectas, curvas y quebradas con altura (aprox. $20 \mathrm{~cm}$ ) logrando un adecuado control postural

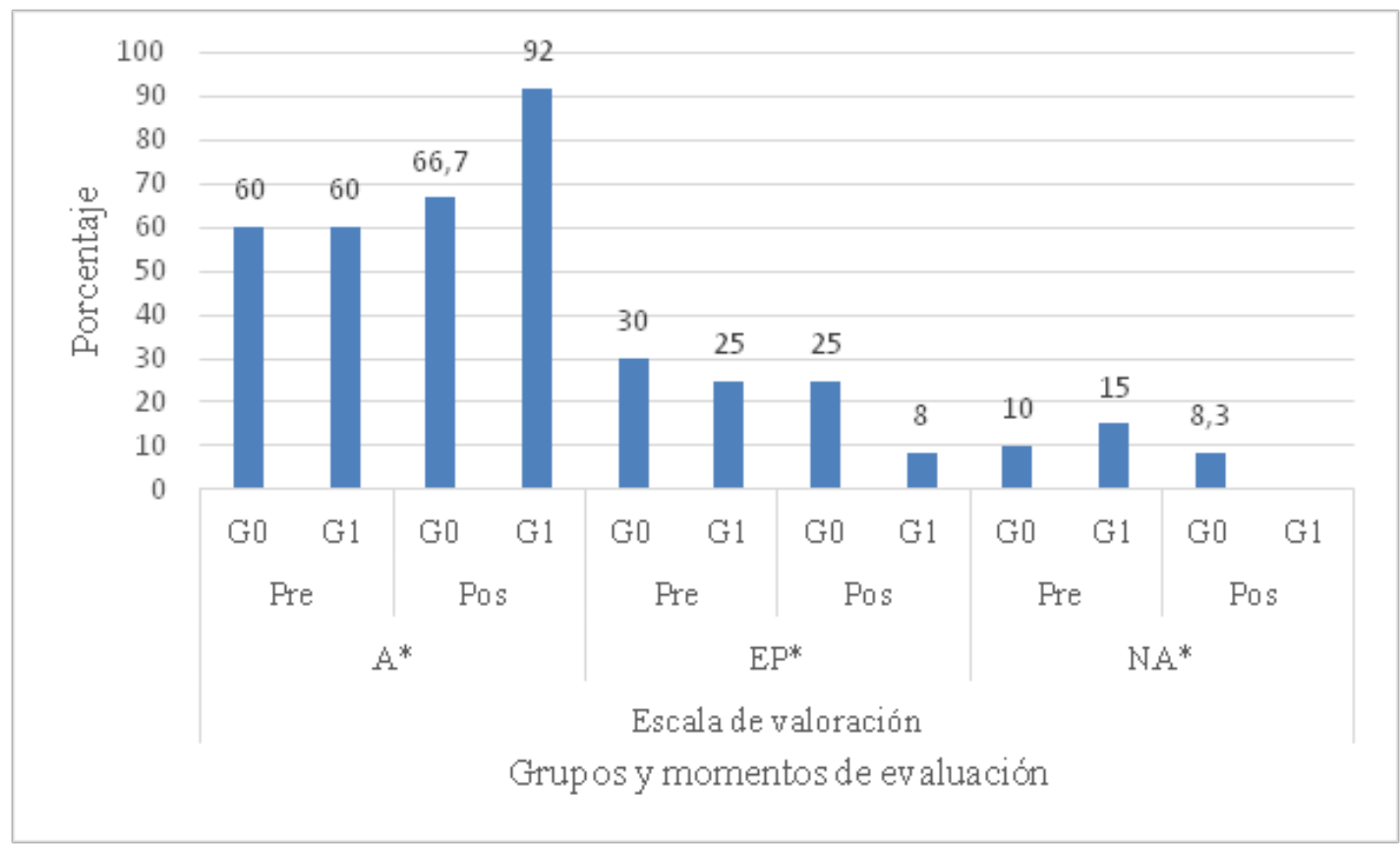


Gráfico No 7. Mantiene un adecuado control postural en diferentes posiciones del cuerpo y en desplazamientos.

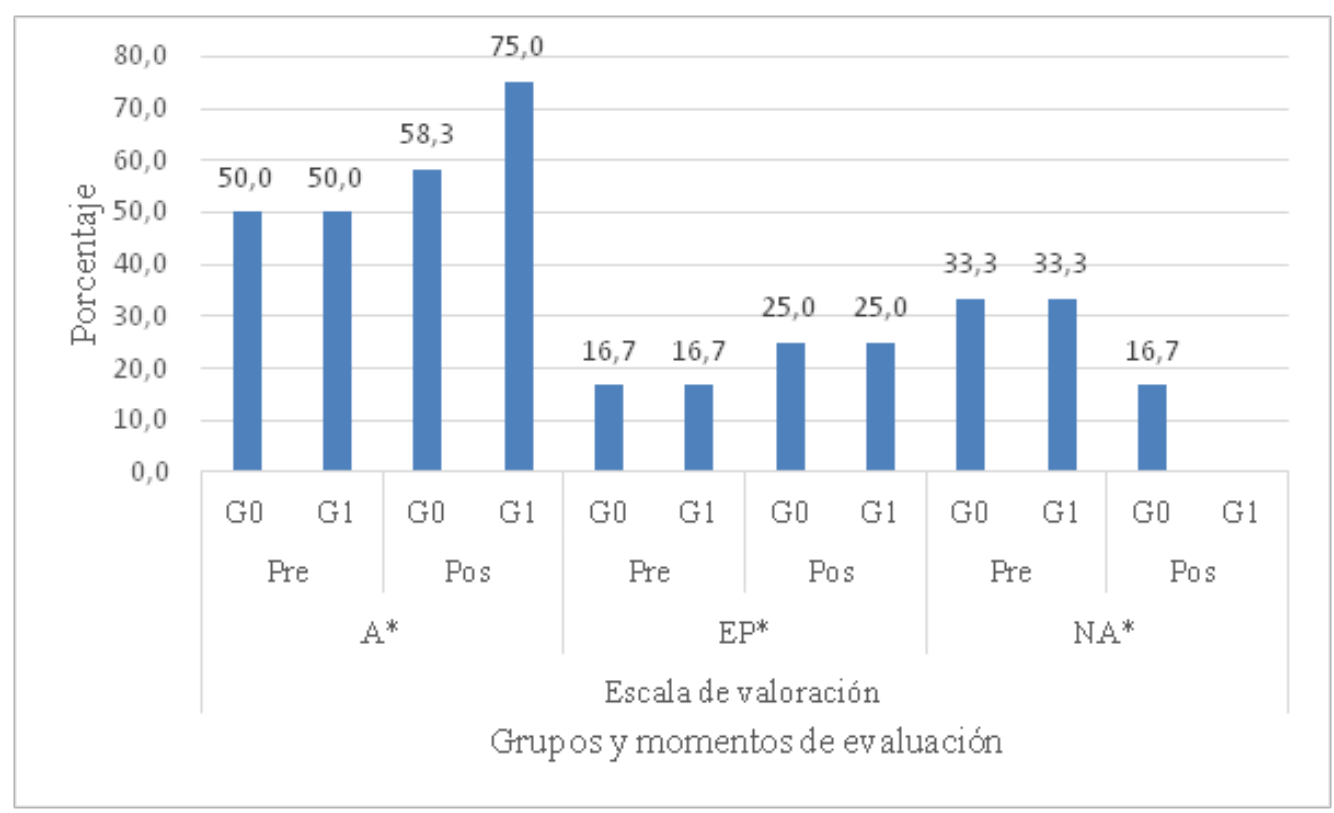

Gráfico No 8. Realiza ejercicios que involucran movimientos segmentados de partes gruesas y finas del cuerpo.

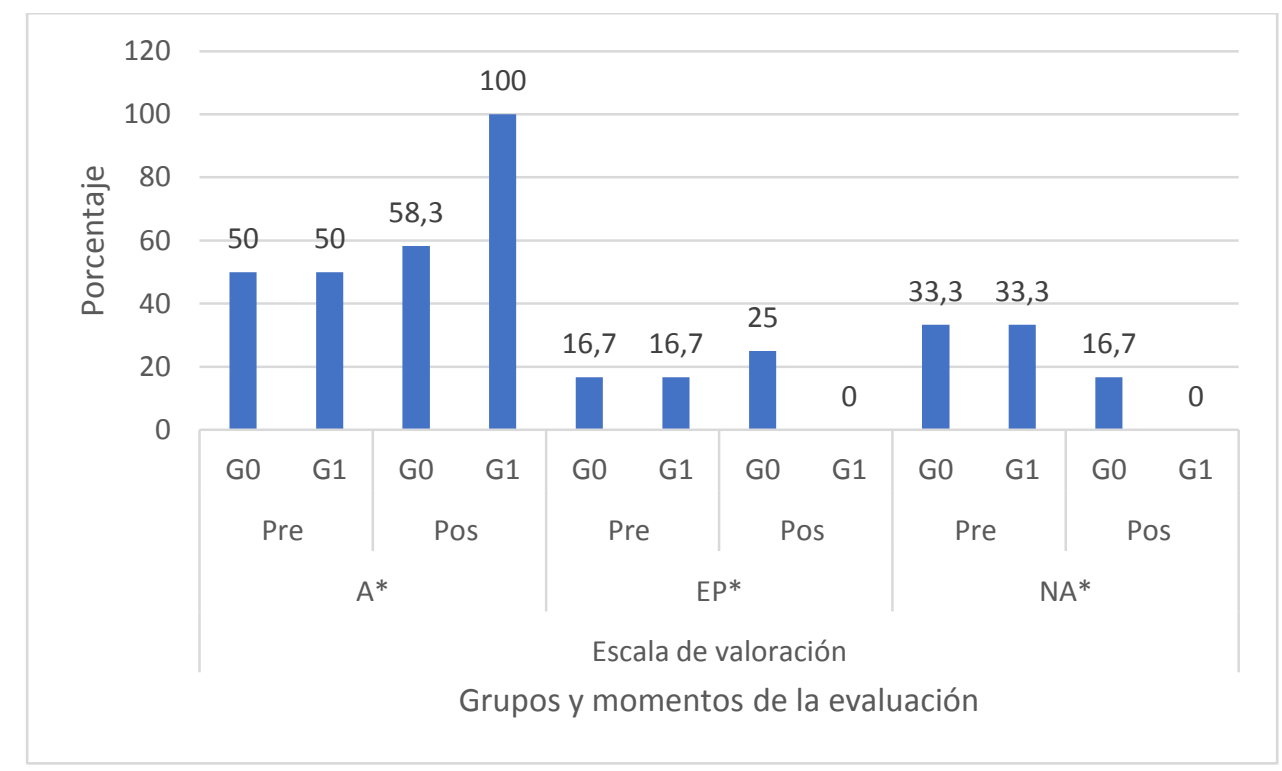




\section{TablaN 5. Desarrollo de la habilidad de coordinación visomotriz de ojomano y pie}

\begin{tabular}{|c|c|c|c|c|c|c|c|c|c|c|c|c|}
\hline \multirow{4}{*}{$\begin{array}{c}\text { Momentos de la } \\
\text { evaluación } \\
\text { Grupos } \\
\text { Criterios }\end{array}$} & \multicolumn{12}{|c|}{ Escala de valoración } \\
\hline & \multicolumn{4}{|c|}{$\mathbf{A}^{*}$} & \multicolumn{4}{|c|}{ EP* } & \multicolumn{4}{|c|}{$I^{*}$} \\
\hline & \multicolumn{2}{|c|}{ Pre } & \multicolumn{2}{|c|}{ Pos } & \multicolumn{2}{|c|}{ Pre } & \multicolumn{2}{|c|}{ Pos } & \multicolumn{2}{|c|}{ Pre } & \multicolumn{2}{|c|}{ Pos } \\
\hline & G0 & G1 & G0 & G1 & G0 & G1 & G0 & G1 & G0 & G1 & G0 & G1 \\
\hline $\begin{array}{l}\text { Realiza actividades } \\
\text { de coordinación } \\
\text { visomotriz con } \\
\text { niveles de dificultad } \\
\text { creciente en el } \\
\text { tamaño y tipo de } \\
\text { materiales }\end{array}$ & 50 & 50 & 58,3 & 83,3 & 16,7 & 16,7 & 25 & 16,7 & 33,3 & 33,3 & 16,7 & 0 \\
\hline $\begin{array}{c}\text { Utiliza la pinza } \\
\text { digital para coger el } \\
\text { objeto de la rayuela } \\
\text { (ficha o teja) y, } \\
\text { lápices, marcadores, } \\
\text { pinceles y diversos } \\
\text { tipos de materiales }\end{array}$ & 75 & 75 & 83,3 & 100 & 25 & 25 & 16,7 & 0 & 0 & 0 & 0 & 0 \\
\hline $\begin{array}{c}\text { Realiza } \\
\text { representaciones } \\
\text { gráficas utilizando el } \\
\text { dibujo con detalles } \\
\text { que le dan } \\
\text { intencionalidad y } \\
\text { sentido para } \\
\text { identificarlos } \\
\end{array}$ & 58,3 & 50 & 75 & 75 & 25 & 25 & 16,7 & 25 & 16,7 & 25 & 8,3 & 0 \\
\hline $\begin{array}{c}\text { Realiza } \\
\text { movimientos para la } \\
\text { coordinación de ojo } \\
\text { y pie como: empujar } \\
\text { la piedra del juego } \\
\text { de la rayuela hacia } \\
\text { un punto fijo } \\
\text { determinado. }\end{array}$ & 50 & 50 & 58,3 & 100 & 16,7 & 16,7 & 25 & 0 & 33,3 & 33,3 & 16,7 & 0 \\
\hline
\end{tabular}

Gráfico No9. Realiza actividades de coordinación visomotriz con niveles de dificultad creciente en el tamaño y tipo de materiales.

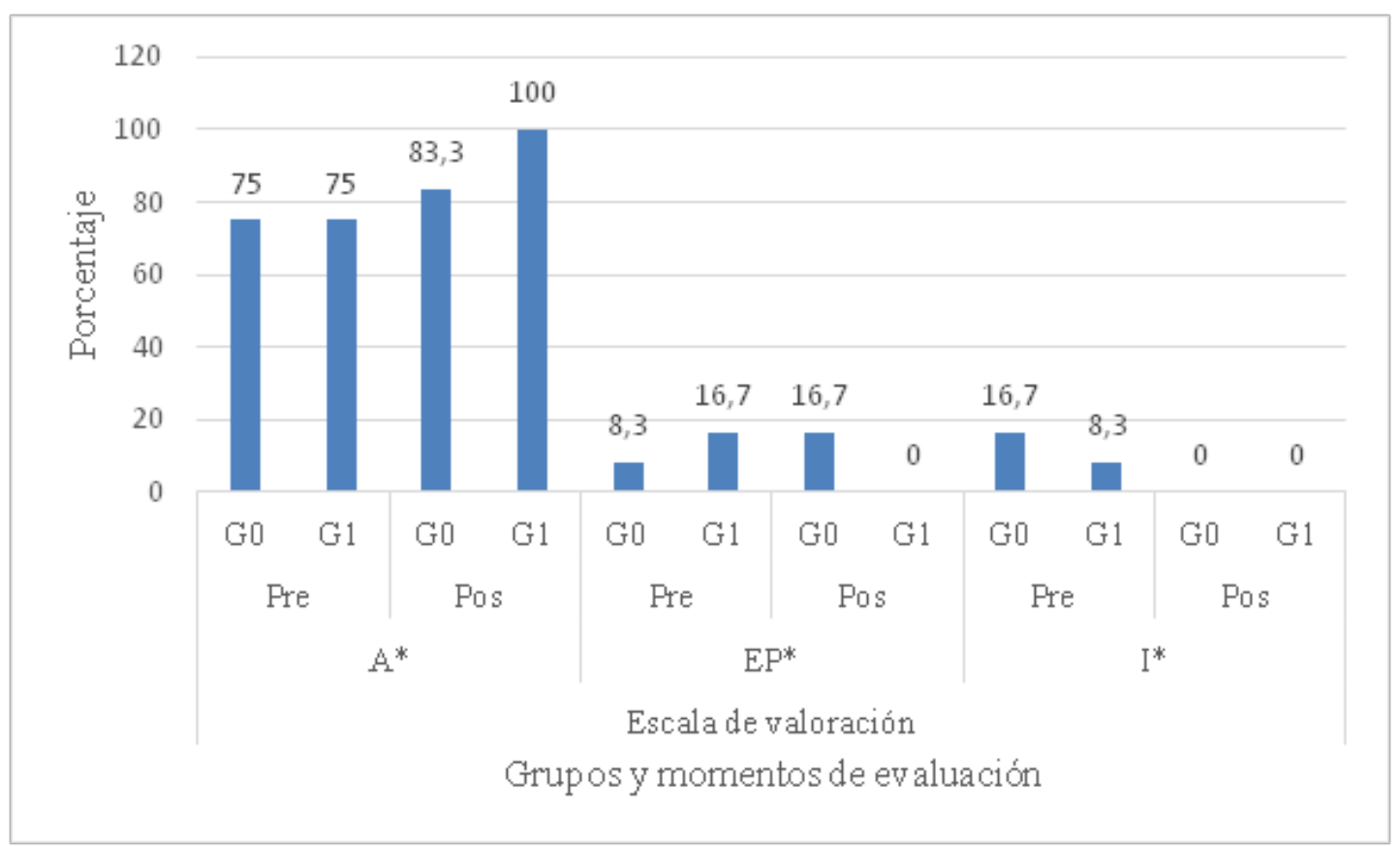


Gráfico No10. Utiliza la pinza digital para coger el objeto de la rayuela (ficha o teja) y, lápices, marcadores, pinceles y diversos tipos de materiales.

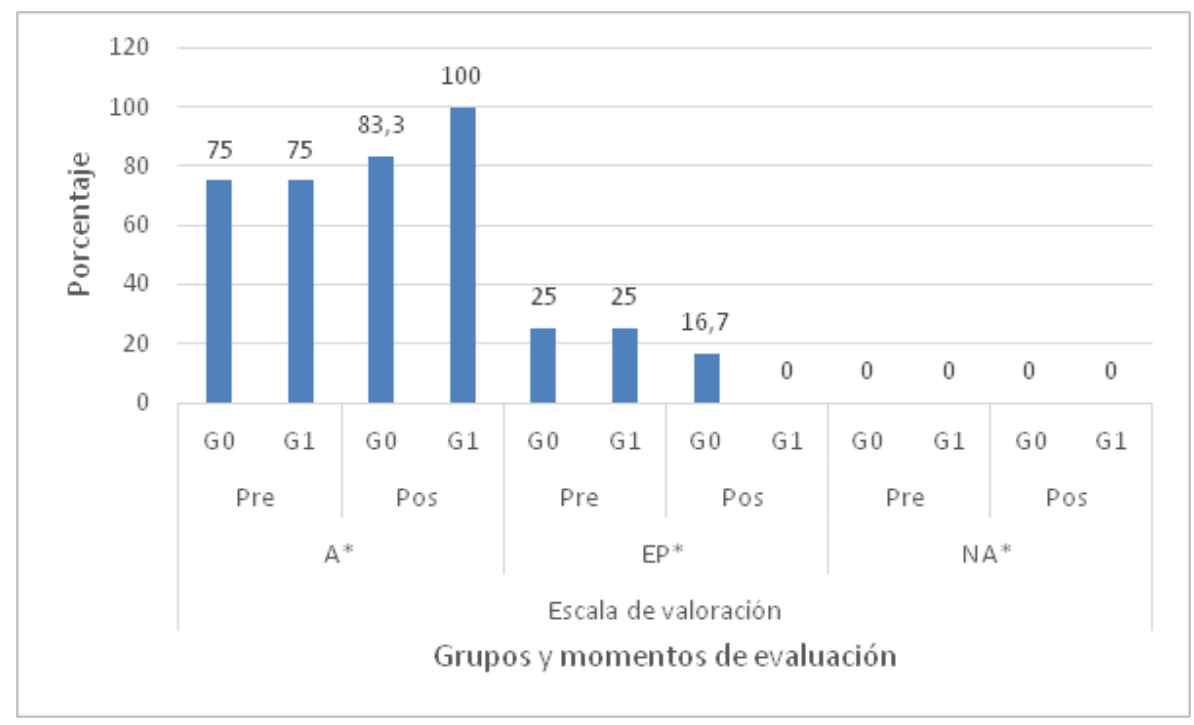

Gráfico $\mathrm{N}^{\circ} 11$. Realiza representaciones gráficas utilizando el dibujo con detalles que le dan intencionalidad y sentido para identificarlos.

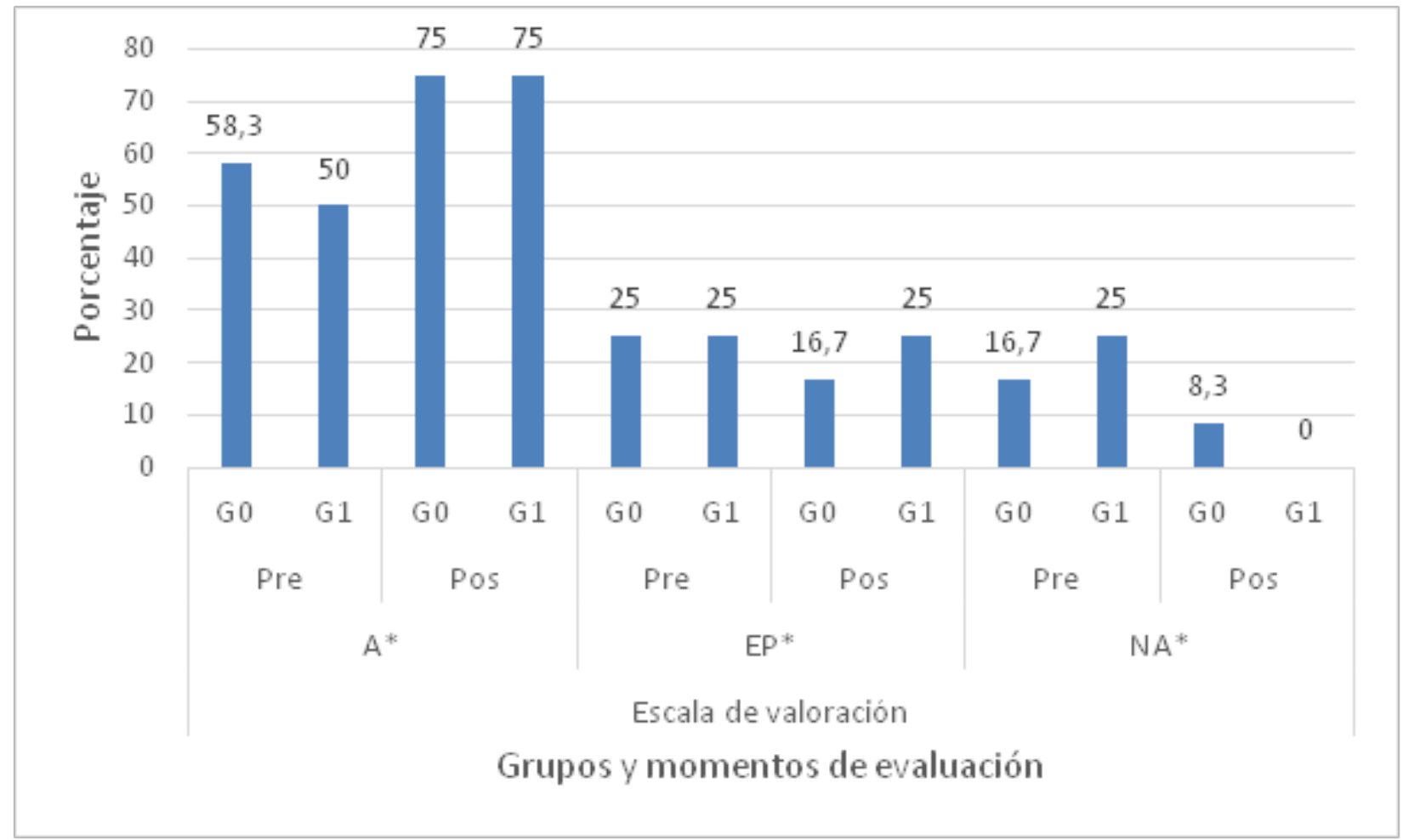


Gráfico $\mathrm{N}^{\circ} 12$ Realiza movimientos para la coordinación de ojo y pie (empujar la piedra del juego de la rayuela hacia un punto fijo determinado).

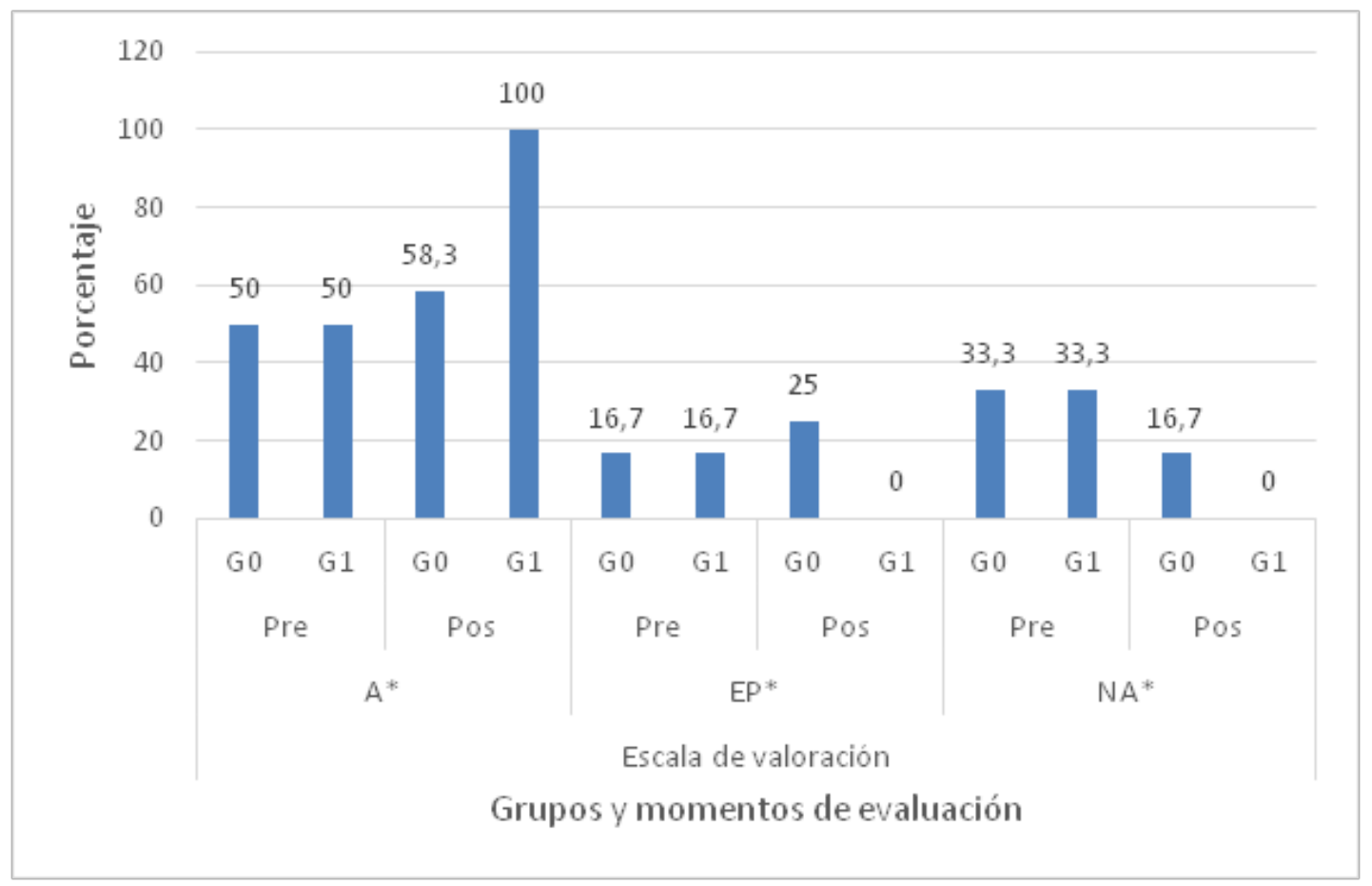

Tabla No6. Estructura su esquema corporal a través de la exploración sensorial para lograr la interiorización de una adecuada imagen corporal.

\begin{tabular}{|c|c|c|c|c|c|c|c|c|c|c|c|c|}
\hline \multirow{4}{*}{$\begin{array}{c}\text { Momentos de la } \\
\text { evaluación } \\
\text { Grupos } \\
\text { Criterios }\end{array}$} & \multicolumn{12}{|c|}{ Escala de valoración } \\
\hline & \multicolumn{4}{|c|}{$\mathbf{A}^{*}$} & \multicolumn{4}{|c|}{ EP* } & \multicolumn{4}{|c|}{$I^{*}$} \\
\hline & \multicolumn{2}{|c|}{ Pre } & \multicolumn{2}{|c|}{ Pos } & \multicolumn{2}{|c|}{ Pre } & \multicolumn{2}{|c|}{ Pos } & \multicolumn{2}{|c|}{ Pre } & \multicolumn{2}{|c|}{ Pos } \\
\hline & G0 & G1 & G0 & G1 & G0 & G1 & G0 & G1 & G0 & G1 & G0 & G1 \\
\hline \begin{tabular}{|} 
Identifica en su cuerpo y \\
en el de los demás partes \\
y articulaciones del \\
cuerpo humano, así \\
como partes finas de la \\
cara, a través de la \\
exploración sensorial \\
\end{tabular} & 75 & 75 & 83,3 & 100 & 8,3 & 16,7 & 16,7 & 0 & 16,7 & 8,3 & 0 & 0 \\
\hline \begin{tabular}{|c|} 
Representa la figura \\
humana utilizando el \\
monigote e incorporando \\
detalles según la \\
interiorización de su \\
imagen corporal \\
\end{tabular} & 75 & 75 & 83,3 & 100 & 25 & 25 & 16,7 & 0 & 0 & 0 & 0 & 0 \\
\hline \begin{tabular}{|c|} 
Emplea su lado \\
dominante en la \\
realización de la \\
mayoría de las \\
actividades que utilice la \\
mano, ojo y pie. \\
\end{tabular} & 58,3 & 58,3 & 83,3 & 100 & 25 & 25 & 16,7 & 25 & 16,7 & 25 & 8,3 & 0 \\
\hline $\begin{array}{c}\text { Realiza movimientos } \\
\text { para la coordinación de } \\
\text { ojo y pie como: empujar } \\
\text { la piedra del juego de la } \\
\text { rayuela hacia un punto } \\
\text { fijo determinado. }\end{array}$ & 75 & 75 & 83,3 & 100 & 8,3 & 16,7 & 16,7 & 0 & 16,7 & 8,3 & 0 & 0 \\
\hline
\end{tabular}


Gráfico $\mathrm{N}^{\circ} 13$. Identifica en su cuerpo y en el de los demás partes y articulaciones del cuerpo humano, así como partes finas de la cara, a través de la exploración sensorial

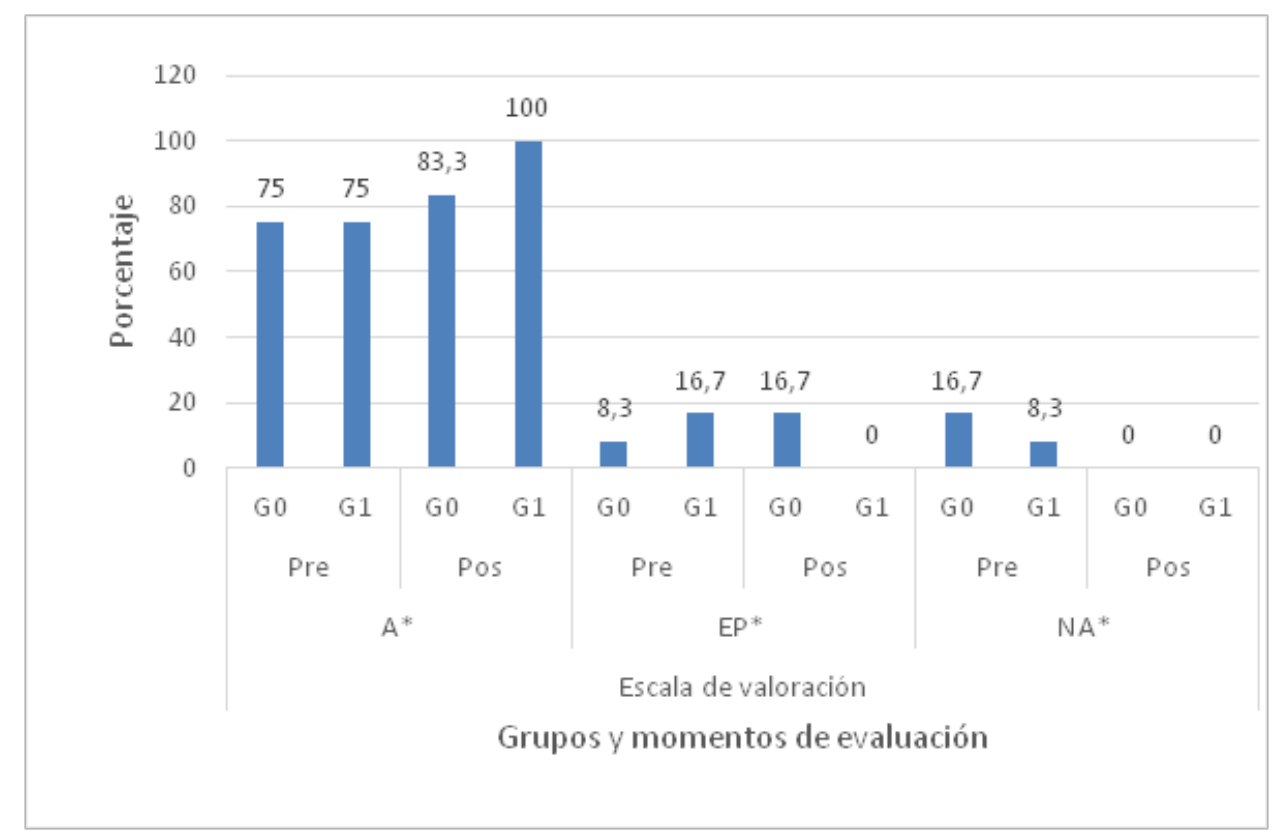

Gráfico $N^{\circ} 14$. Representa la figura humana utilizando el monigote e incorporando detalles según la interiorización de su imagen corporal.

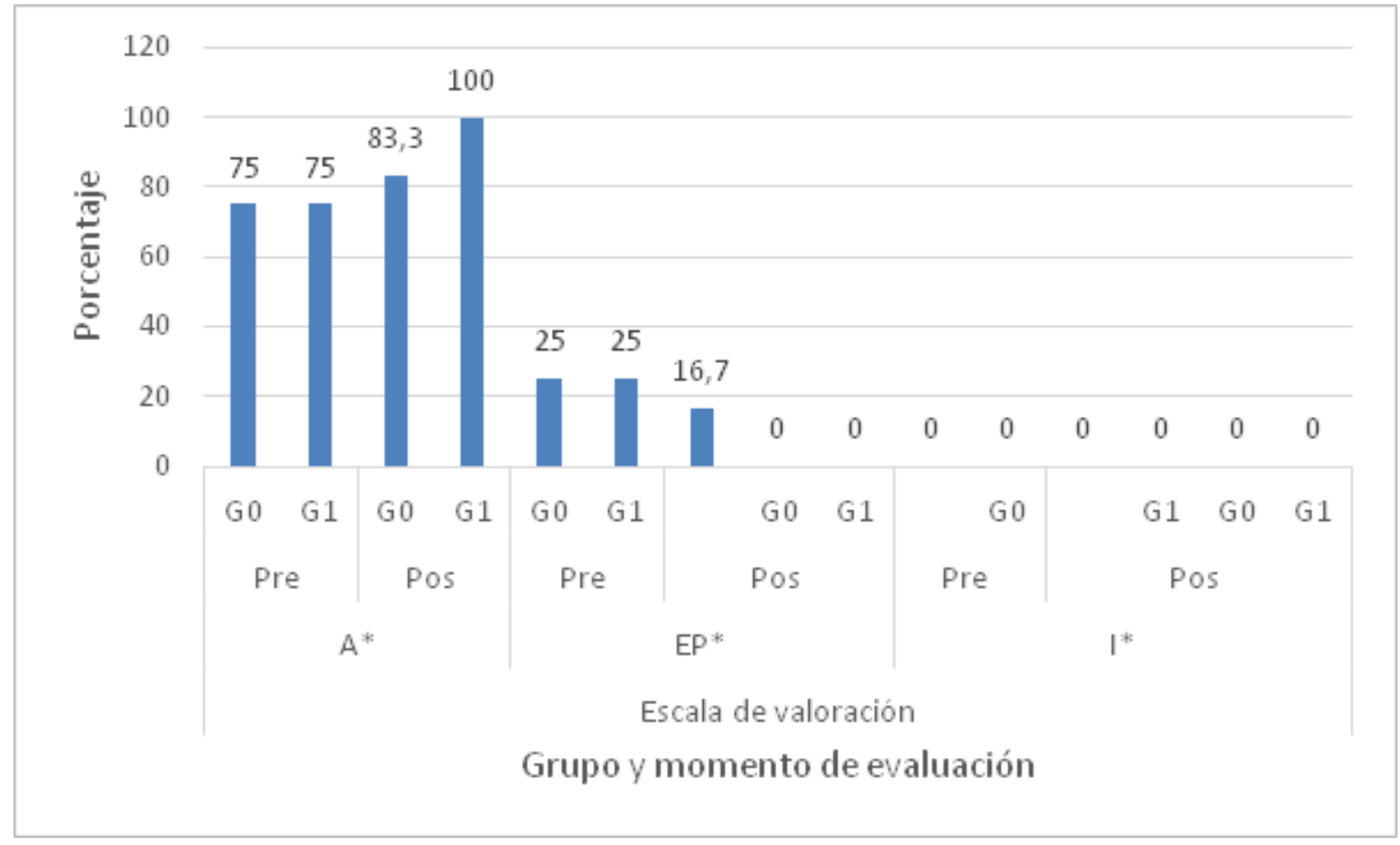


Gráfico $\mathrm{N}^{\circ} 15$. Emplea su lado dominante en la realización de la mayoría de las actividades que utilice la mano, ojo y pie.

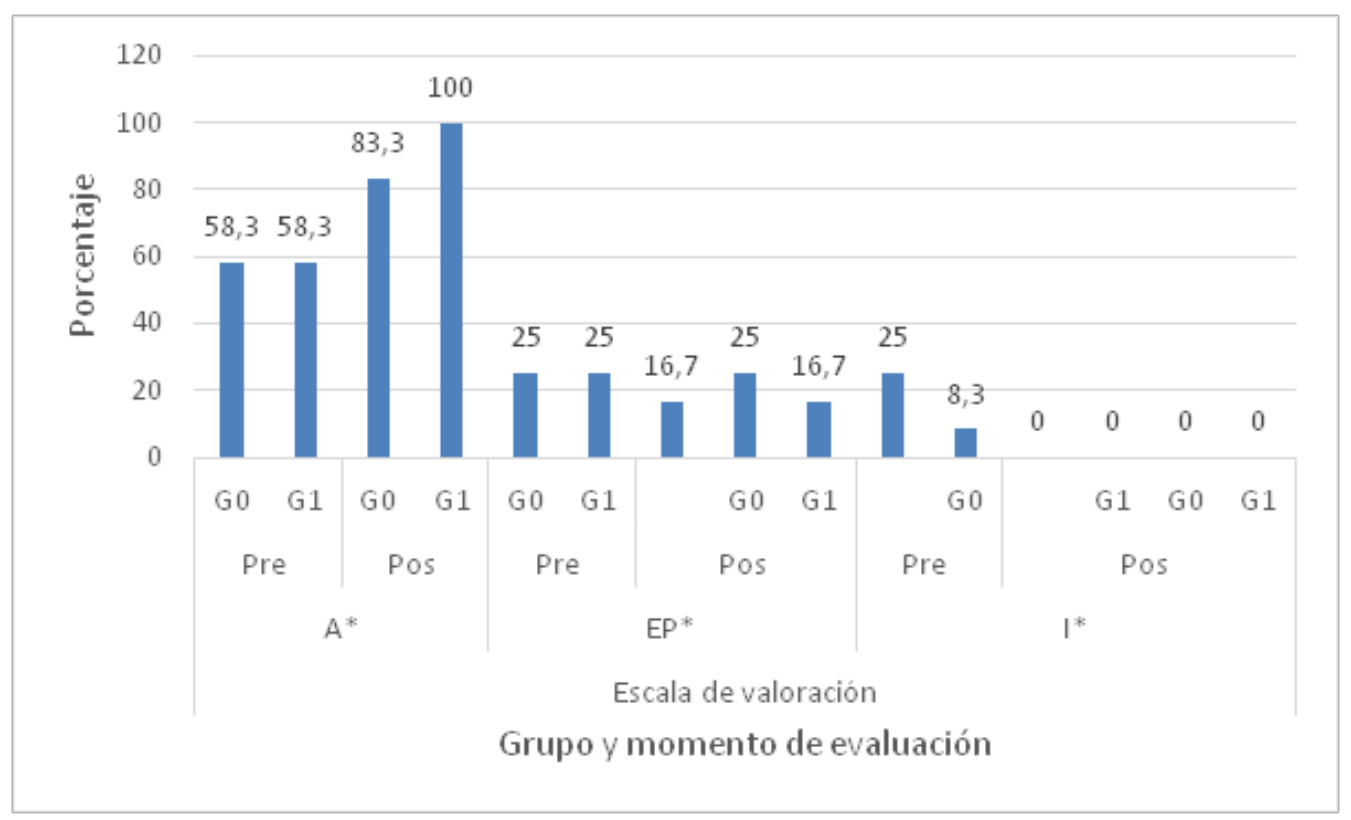

Gráfico ํo 16 . Emplea su lado dominante en la realización de la mayoría de las actividades que utilice la mano, ojo y pie.

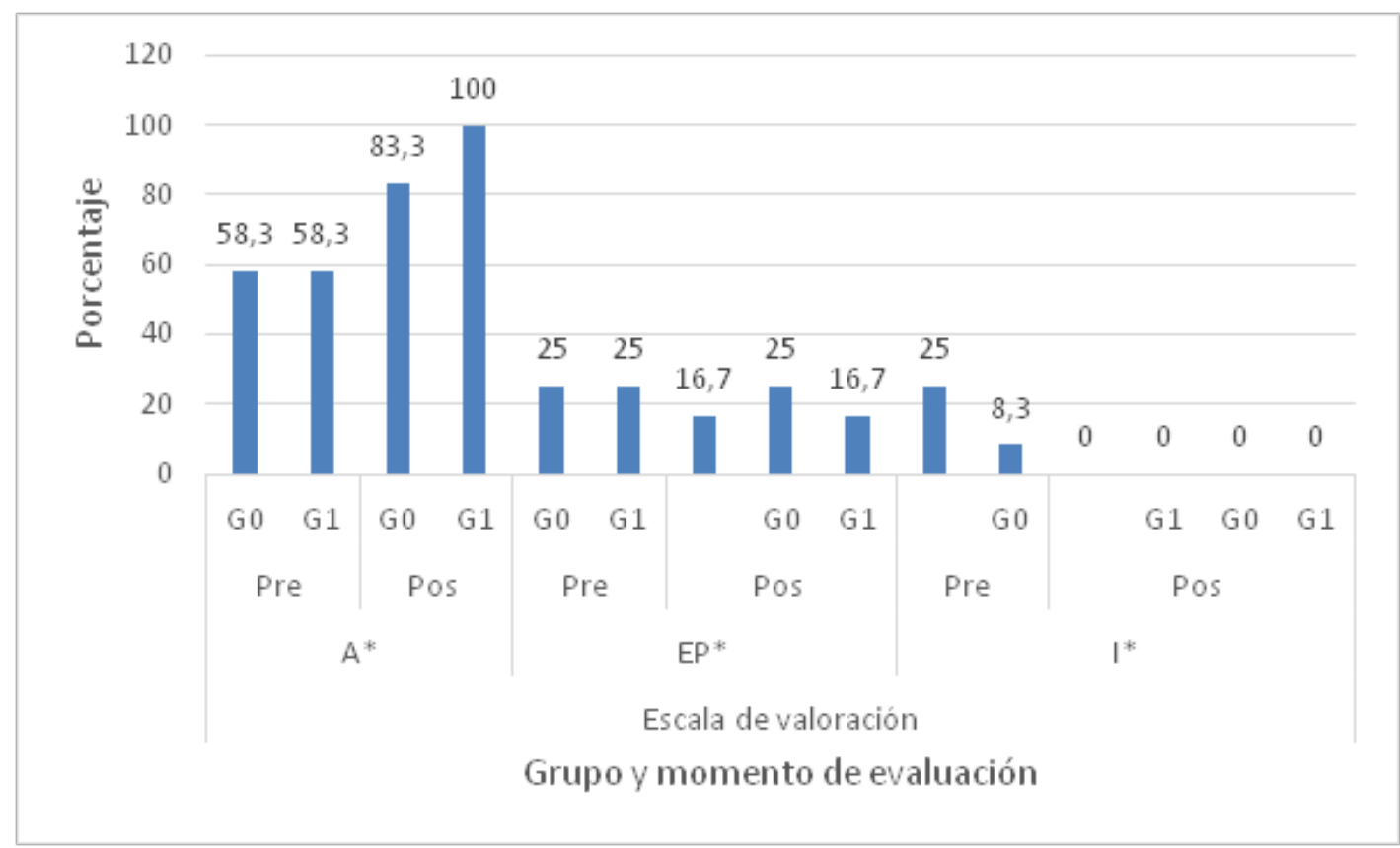


Tabla $N^{\circ}$. Interioriza la propia simetría corporal tomando conciencia de la igualdad de ambos lados y coordinando la movilidad de las dos áreas longitudinales.

\begin{tabular}{|c|c|c|c|c|c|c|c|c|c|c|c|c|}
\hline \multirow{4}{*}{$\begin{array}{c}\text { Momentos de la } \\
\text { evaluación } \\
\text { Grupos } \\
\text { Criterios }\end{array}$} & \multicolumn{12}{|c|}{ Escala de valoración } \\
\hline & \multicolumn{4}{|c|}{$A^{*}$} & \multicolumn{4}{|c|}{ EP* } & \multicolumn{4}{|c|}{$I^{*}$} \\
\hline & \multicolumn{2}{|c|}{ Pre } & \multicolumn{2}{|c|}{ Pos } & \multicolumn{2}{|c|}{ Pre } & \multicolumn{2}{|c|}{ Pos } & \multicolumn{2}{|c|}{ Pre } & \multicolumn{2}{|c|}{ Pos } \\
\hline & G0 & G1 & G0 & G1 & G0 & G1 & G0 & G1 & G0 & G1 & G0 & G1 \\
\hline $\begin{array}{c}\text { Realiza ejercicios de } \\
\text { simetría corporal como: } \\
\text { identificar en el espejo y } \\
\text { otros materiales las } \\
\text { partes semejantes que } \\
\text { conforman el lado } \\
\text { derecho e izquierdo del } \\
\text { cuerpo }\end{array}$ & 58,3 & 58,3 & 83,3 & 100 & 25 & 25 & 16,7 & 25 & 16,7 & 25 & 8,3 & 0 \\
\hline $\begin{array}{l}\text { Realiza movimientos } \\
\text { diferenciados con los } \\
\text { lados laterales del cuerpo } \\
\text { (un lado y otro lado). }\end{array}$ & 75 & 75 & 83,3 & 100 & 25 & 25 & 16,7 & 0 & 0 & 0 & 0 & 0 \\
\hline
\end{tabular}

Gráfico No17. Realiza ejercicios de simetría corporal como: identifica en el espejo y otros materiales las partes semejantes que conforman el lado derecho e izquierdo del cuerpo.

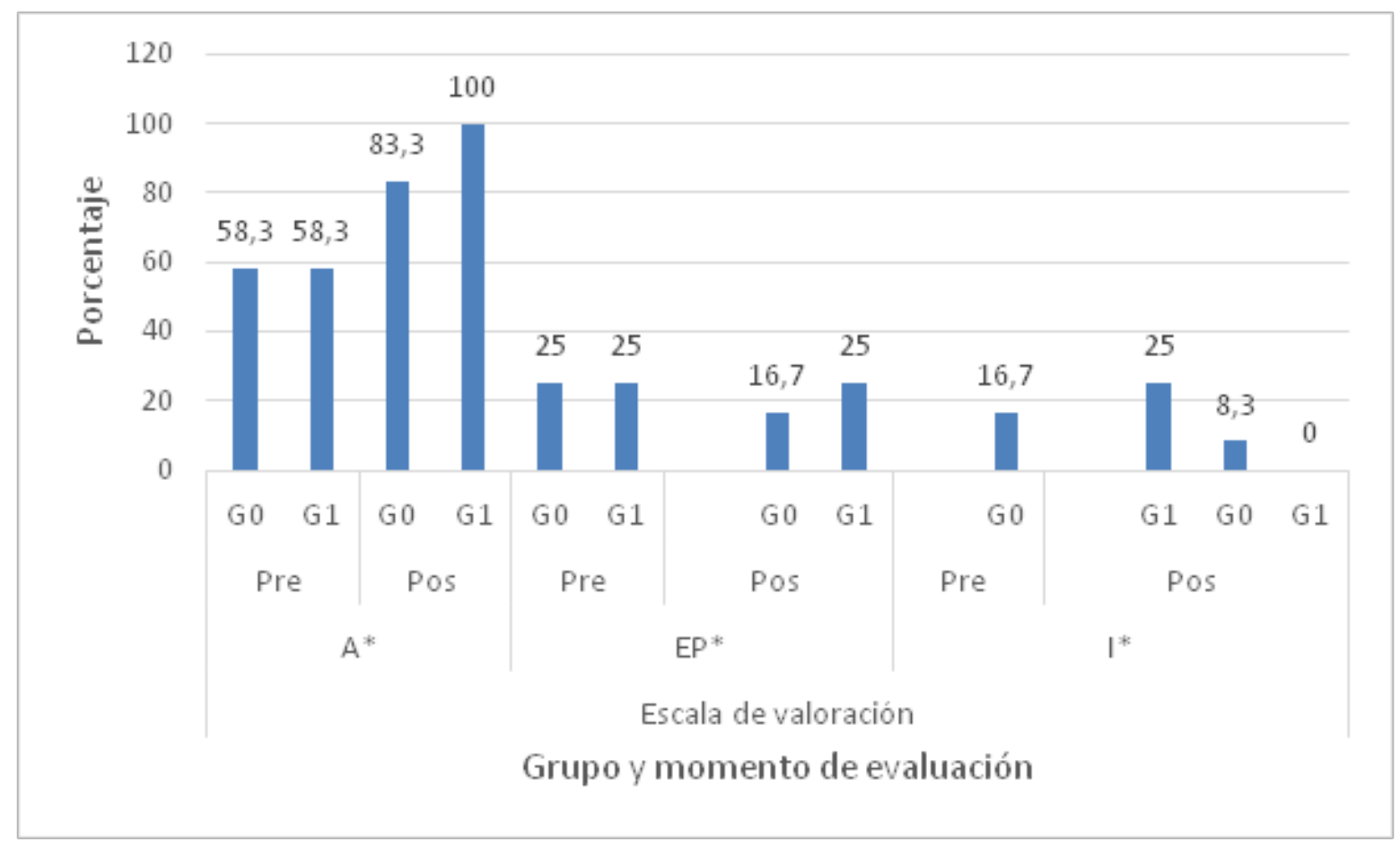


Gráfico $\mathrm{N}^{\circ} 18$. Realiza movimientos diferenciados con los lados laterales del cuerpo (un lado y otro lado).

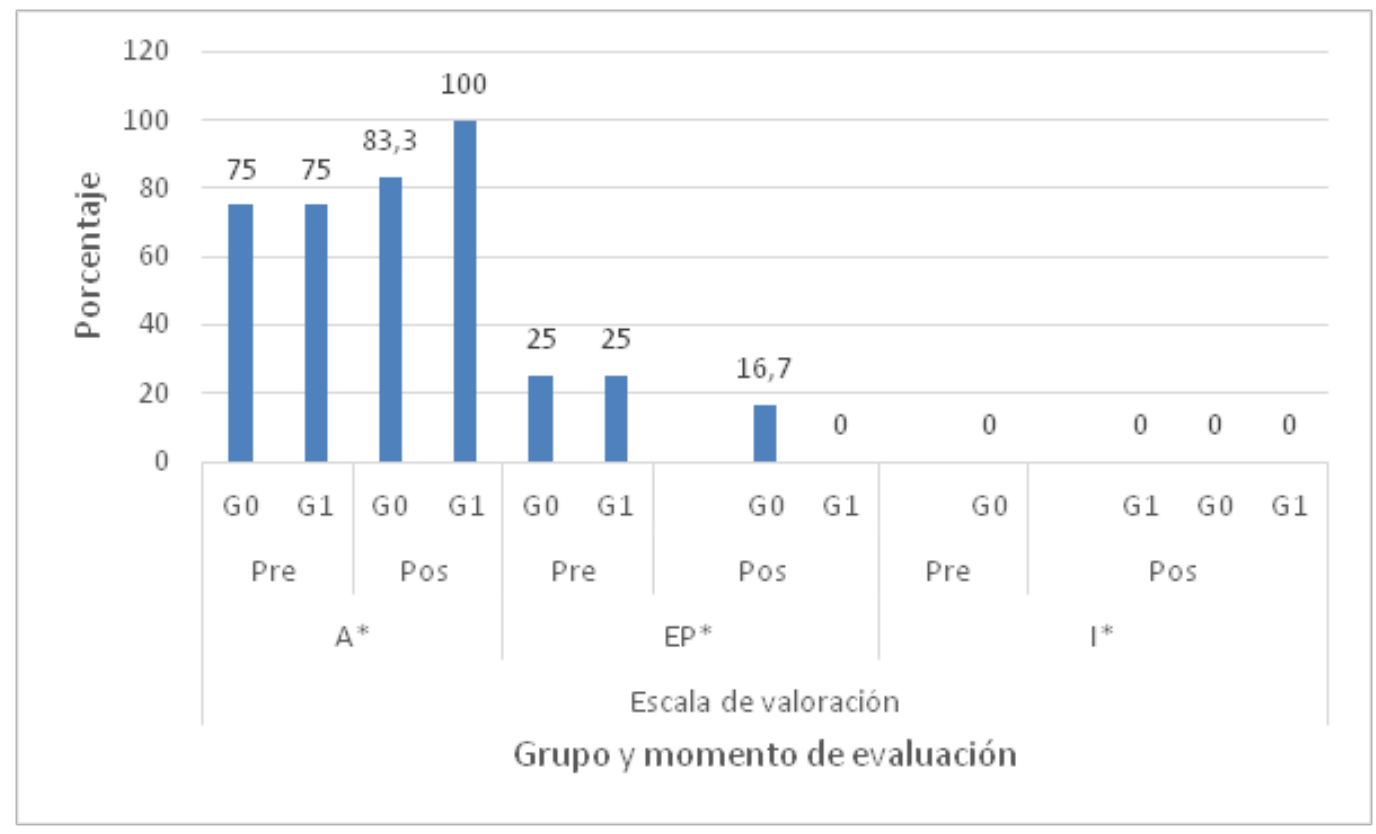

Tabla No8. Desarrollo de la estructuración temporo-espacial a través del manejo de nociones básicas para una mejor orientación de sí mismo en relación al espacio y al tiempo.

\begin{tabular}{|c|c|c|c|c|c|c|c|c|c|c|c|c|}
\hline \multirow{4}{*}{$\begin{array}{l}\text { Momentos de } \\
\text { la evaluación } \\
\text { Grupos } \\
\text { Criterios }\end{array}$} & \multicolumn{12}{|c|}{ Escala de valoración } \\
\hline & \multicolumn{4}{|c|}{$\mathbf{A}^{*}$} & \multicolumn{4}{|c|}{ EP* } & \multicolumn{4}{|c|}{$I^{*}$} \\
\hline & \multicolumn{2}{|c|}{ Pre } & \multicolumn{2}{|c|}{ Pos } & \multicolumn{2}{|c|}{ Pre } & \multicolumn{2}{|c|}{ Pos } & \multicolumn{2}{|c|}{ Pre } & \multicolumn{2}{|c|}{ Pos } \\
\hline & G0 & G1 & G0 & G1 & G0 & G1 & G0 & G1 & G0 & G1 & $\begin{array}{c}\mathbf{G} \\
\mathbf{0}\end{array}$ & G1 \\
\hline $\begin{array}{l}\text { Ubica algunas partes de } \\
\text { su cuerpo en función de } \\
\text { las nociones de al lado, } \\
\text { junto a, cerca-lejos }\end{array}$ & 58,3 & 58,3 & 83,3 & 100 & 25 & 25 & 16,7 & 0 & 16,7 & 16,7 & 0 & 0 \\
\hline $\begin{array}{c}\text { Se orienta en el espacio } \\
\text { realizando } \\
\text { desplazamientos en } \\
\text { función de consignas } \\
\text { dadas con las nociones: } \\
\text { entre, adelante-atrás, } \\
\text { junto a, cerca-lejos }\end{array}$ & 75 & 75 & 83,3 & 100 & 25 & 25 & 16,7 & 0 & 0 & 0 & 0 & 0 \\
\hline $\begin{array}{c}\text { Realiza } \\
\text { desplazamientos y } \\
\text { movimientos } \\
\text { combinados utilizando } \\
\text { el espacio total y } \\
\text { parcial a diferentes } \\
\text { distancias (largas- } \\
\text { cortas) } \\
\end{array}$ & 58,3 & 58,3 & 83,3 & 100 & 25 & 33,4 & 16,7 & 0 & 16,7 & 8,3 & 0 & 0 \\
\hline $\begin{array}{c}\text { Utiliza el espacio } \\
\text { parcial e inicia con el } \\
\text { uso del espacio total } \\
\text { para realizar } \\
\text { representaciones } \\
\text { gráficas }\end{array}$ & 75 & 75 & 83,3 & 100 & 8,3 & 16,7 & 16,7 & 0 & 16,7 & 8,3 & 0 & 0 \\
\hline $\begin{array}{c}\text { Realiza varios } \\
\text { movimientos y } \\
\text { desplazamientos } \\
\text { combinados a } \\
\text { diferentes velocidades } \\
\text { (rápido, lento), } \\
\text { duración (largos y } \\
\text { corto). } \\
\end{array}$ & 75 & 75 & 83,3 & 100 & 8,3 & 16,7 & 16,7 & 0 & 16,7 & 8,3 & 0 & 0 \\
\hline
\end{tabular}


Gráfico $\mathrm{N}^{\circ} 19$. Ubica algunas partes de su cuerpo en función de las nociones de al lado, junto a, cerca-lejos.

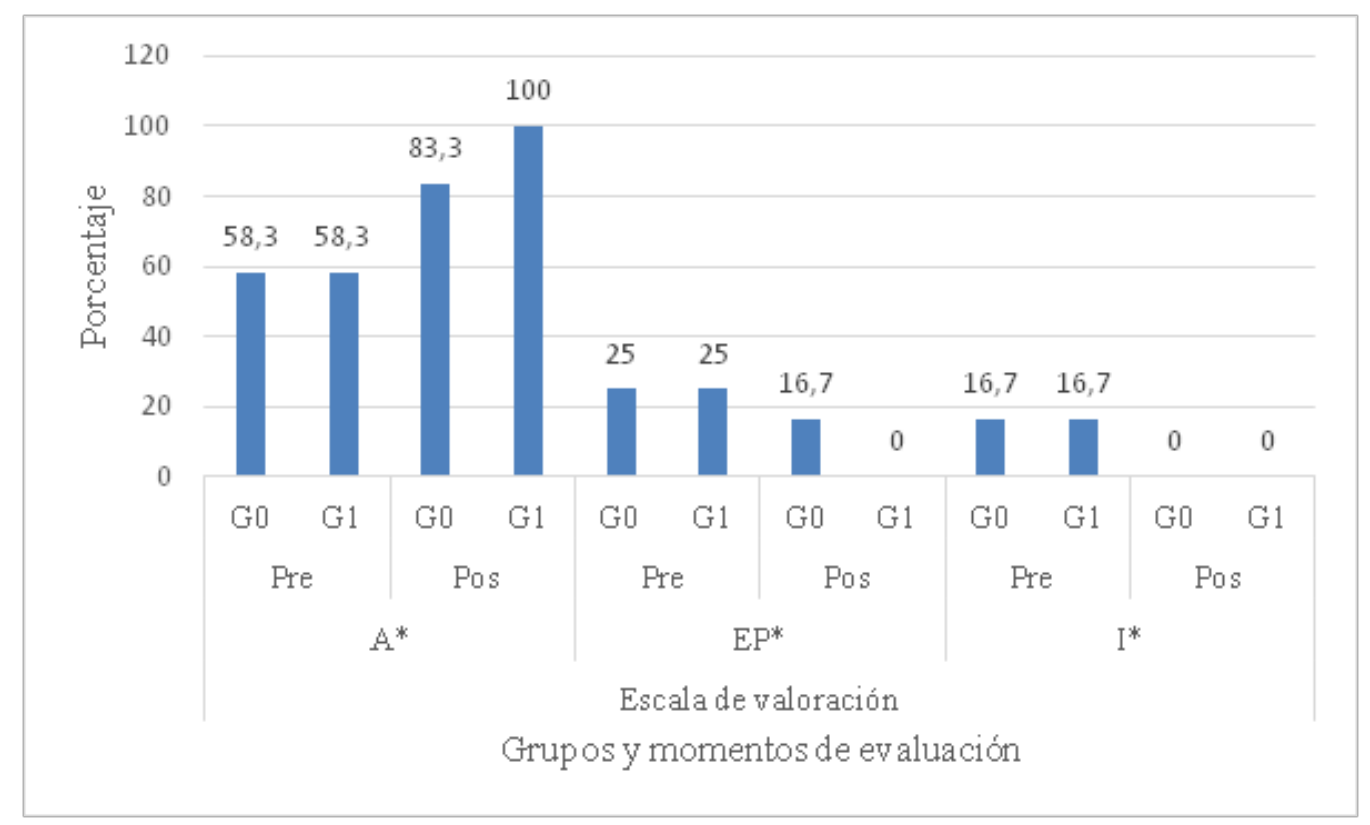

Gráfico No20. Se orienta en el espacio realizando desplazamientos en función de consignas dadas con las nociones: entre, adelante-atrás, junto a, cerca-lejos.

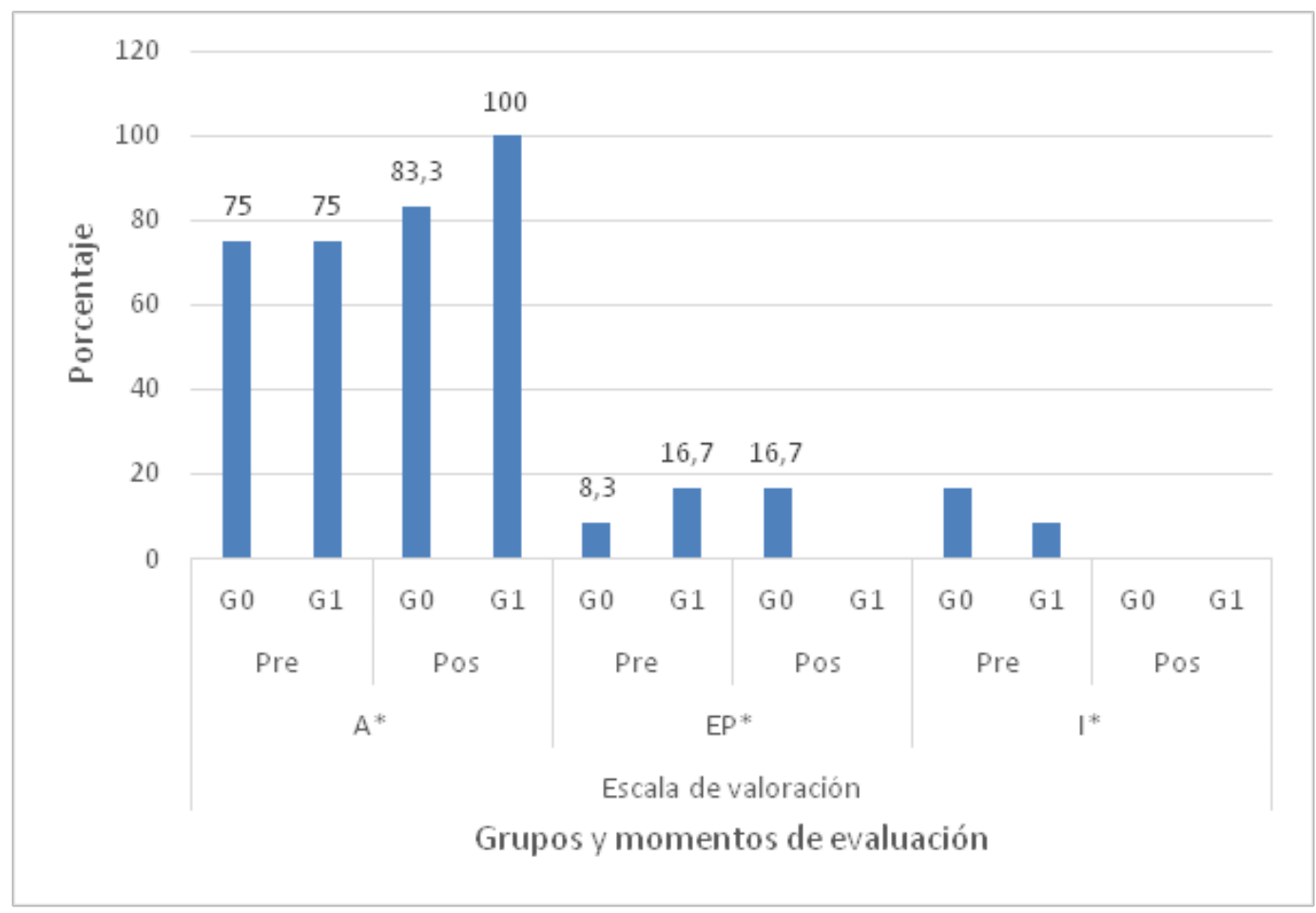


Gráfico $\mathrm{N}^{\circ} 21$. Realiza desplazamientos y movimientos combinados utilizando el espacio total y parcial a diferentes distancias (largas-cortas).

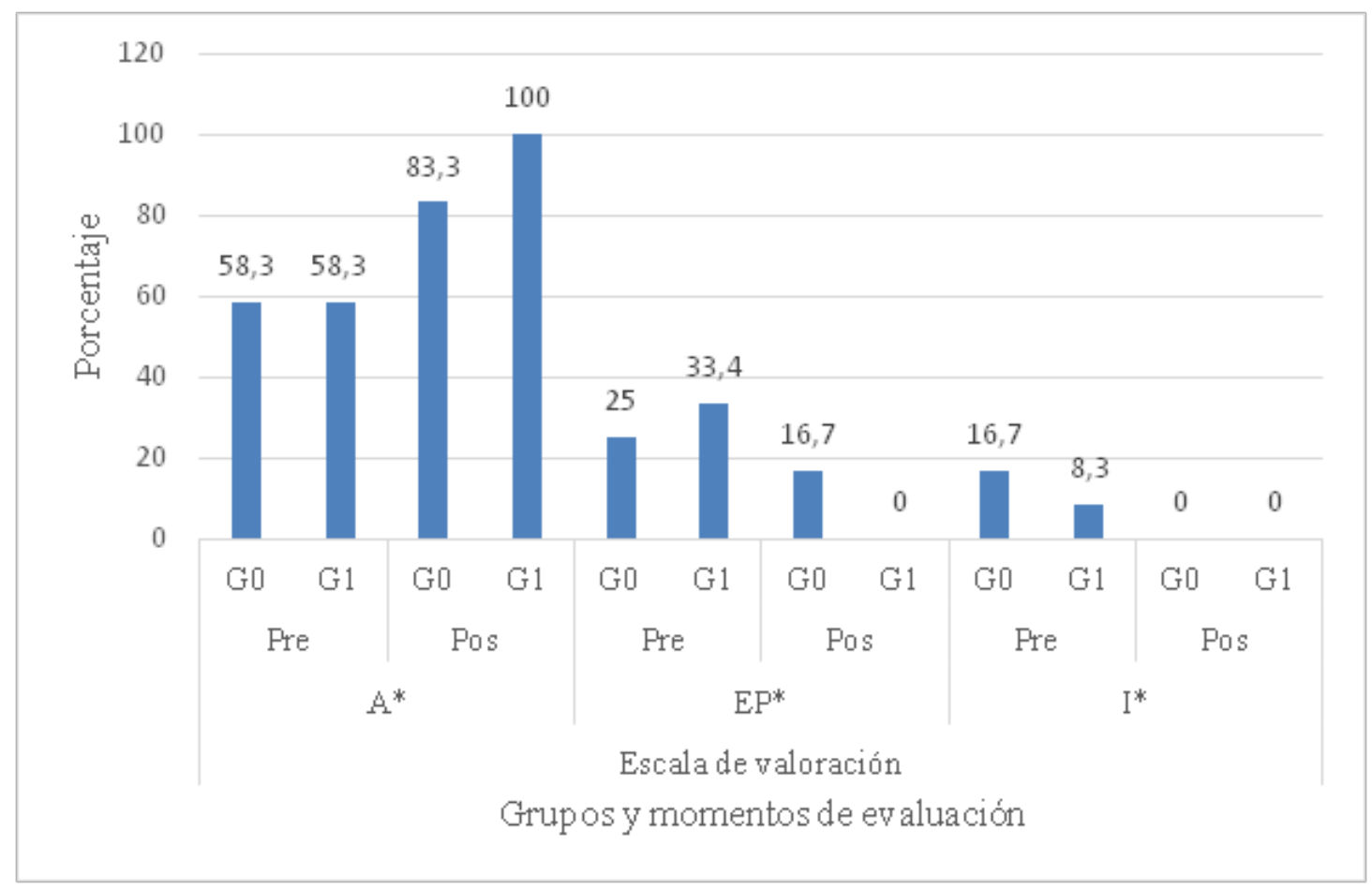

Gráfico No22. Utiliza el espacio parcial e inicia con el uso del espacio total para realizar representaciones gráficas.

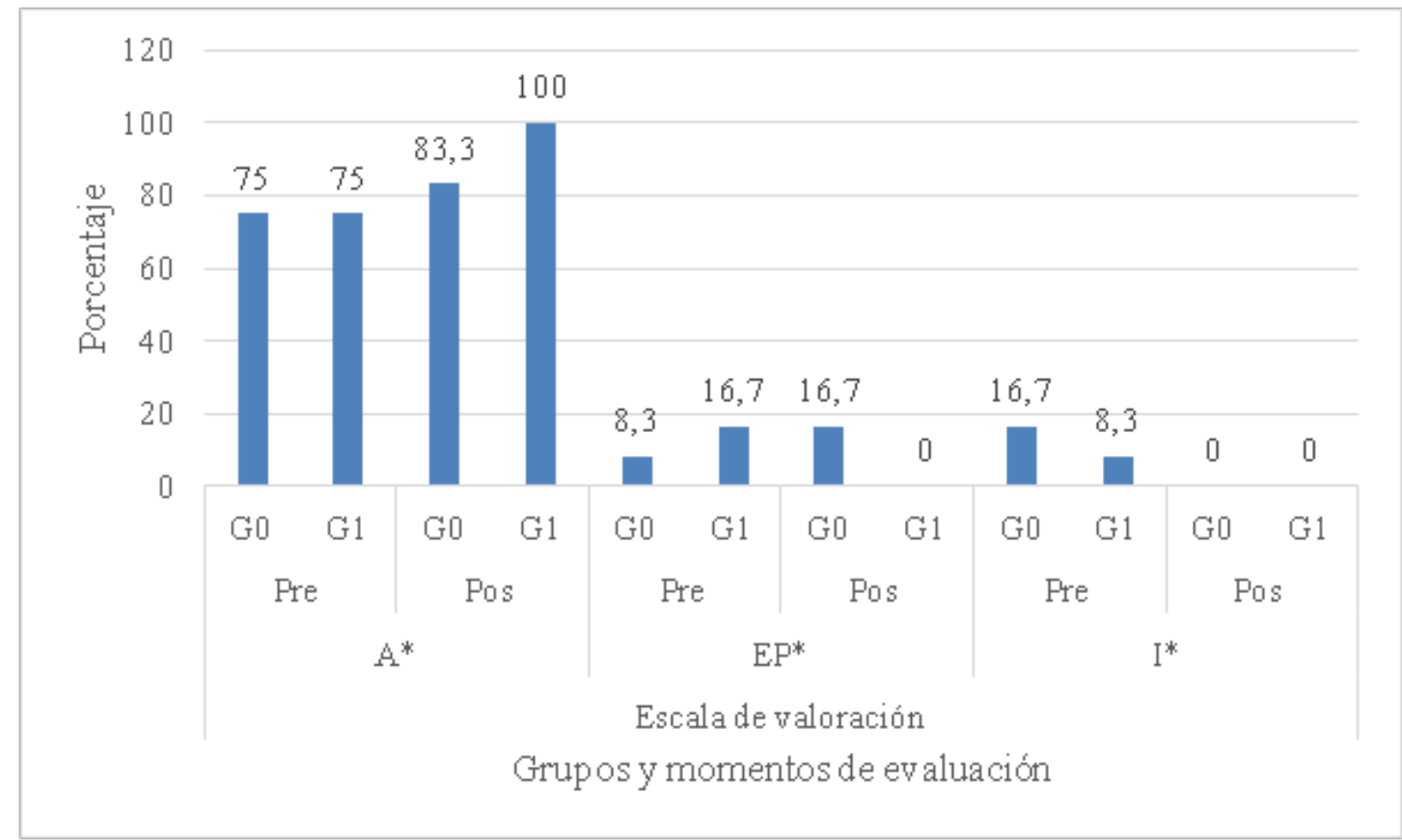




\section{Gráfico No23. Realiza varios movimientos y desplazamientos combinados a diferentes velocidades (rápi-} do, lento), duración (largos y corto).

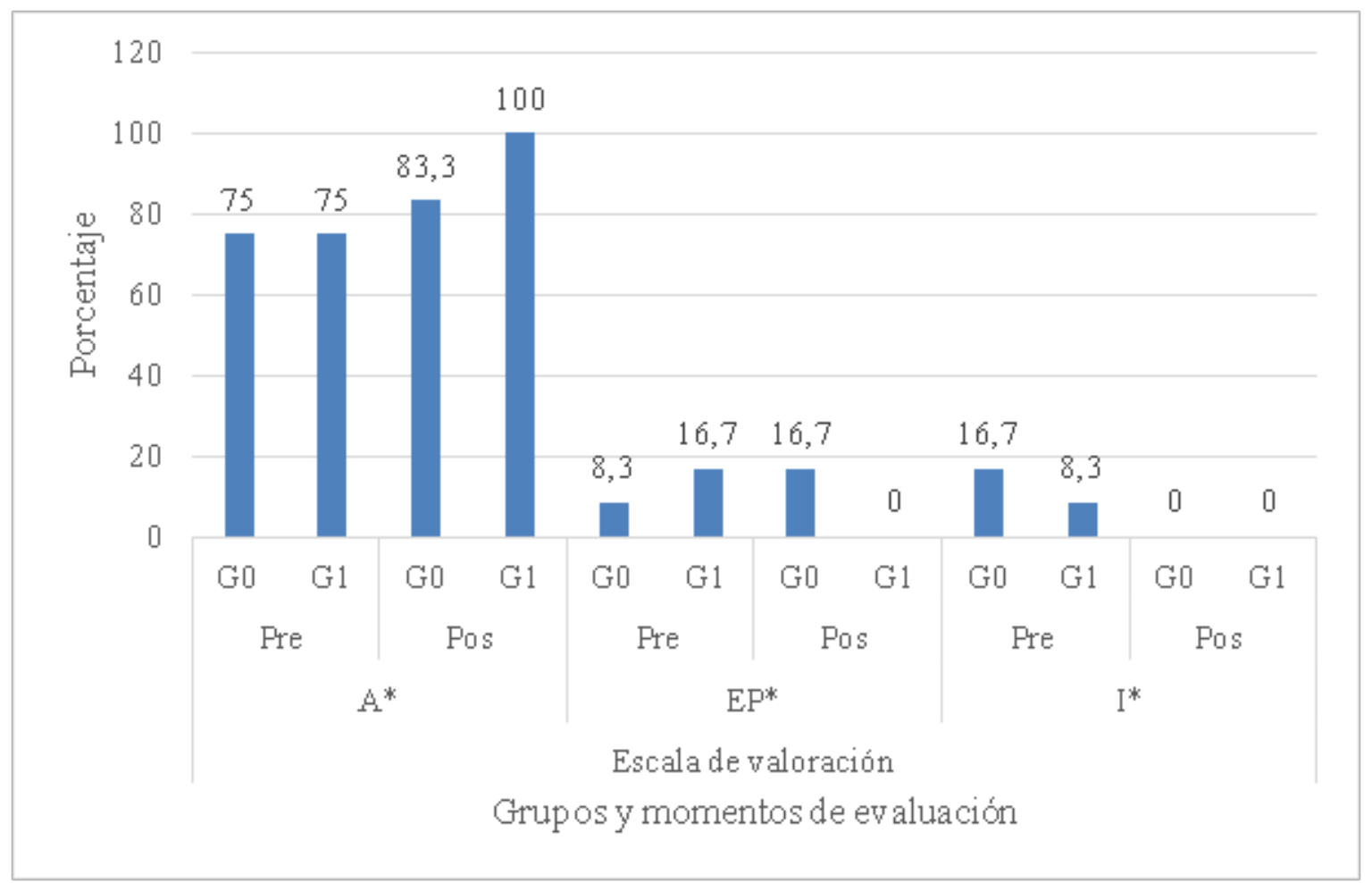

\section{DISCUSIÓN Y CONCLUSIONES}

Al ser la psicomotricidad la disciplina educativa que estudia el desarrollo cognitivo y motriz del niño (Mendieta, Vargas, \& Mendieta, 2017), integra una serie de características motrices, cognitivas y sociales, en el estudio se pudo comprobar que este desarrollo se puede lograr en base a la práctica de juegos tradicionales como la rayuela, la cual tiene un amplio campo de acción, siendo el docente el encargado de crear situaciones que permitan al niño desarrollarse mientras se divierten.

La coordinación dinámica global en sus diferentes formas de locomoción para desplazarse con seguridad, permite el desarrollo del esquema corporal como base de la construcción del niño (Le Boulch, 1997; Lapierre, Llorca, \& Sánchez, 2015), en donde las nociones temporo-espaciales son adquiridas por el niño, que, en un inicio, no tiene ni un espacio único ni un orden temporal que encierren el acto y el objeto de forma discriminada y consciente en un continente global (Piaget \& Inhelder, 2007). Así el niño mejora en la marcha y carrera, la cual la realiza con soltura y seguridad a la vez que mantiene el equilibrio a diferentes distancias, se orienta y tiene ritmo secuenciado en el desarrollo del juego de la rayuela, logrando saltar en sentido vertical hasta aproximadamente unos $30 \mathrm{~cm}$, y en sentido horizontal unos $70 \mathrm{~cm}$. Además, logra saltar en un solo pie de forma autónoma.

El juego de la rayuela permite, el control de la fuerza, en la acción de lanzar la ficha o teja, esta acción permite un control óculo-manual y un dominio temporo-espacial, ya que deben controlar las distancias al lanzar, esto a su vez, permite la consecución de la memoria muscular (Mendieta, Vargas, \& Mendieta, 2017), además, permite que se mejore en el agarre y esto desarrolla la pinza digital, la cual sirve para la escritura y otras actividades en el contexto escolar del infante y de la vida diaria. 
Se mejora en el control postural, debido a las actividades de equilibrio estático y dinámico que tiene la rayuela en su ejecución, con esto también, una mejora en cuanto a la mecánica de caminar, correr o saltar. El juego de la rayuela, ayuda a la percepción de su cuerpo y el de los demás, al dominio y disponibilidad corporal y motora y a la comunicación (Mineduc. 2017), esto se logra a través de la coordinación que adquiere el niño en la realización de movimientos segmentarios identificando la disociación entre las partes gruesas y finas del cuerpo, ya que se trabaja movimientos coordinados del tren inferior, pero, con la coordinación global del cuerpo. La rayuela ayuda de igual forma, al desarrollo de la coordinación óculo-manual y óculo-podal.

Se coincide con Mendieta, Vargas, \& Mendieta, (2017) en cuanto al desarrollo de la lateralidad, la cual es otra de las propiedades que el niño desarrolla, proyectándola a su exterior, ya que logra interiorizar las dos áreas longitudinales, laterales del cuerpo, de igual manera, realiza ejercicios de simetría corporal como: identificar el lado derecho e izquierdo del cuerpo, realizando movimientos diferenciados con los lados laterales del cuerpo.

El juego sirve, además, para el desarrollo de las relaciones lógico-matemáticas (Torbert, 1982). Además de conseguirse la estructuración temporo-espacial a través del manejo de nociones básicas, el juego de la rayuela permite al niño conocer bajo las consignas propias del juego, nociones: entre, adelante-atrás, junto a, cerca-lejos; conoce también, distancias largas-cortas; y discrimina entre desplazamientos combinados a diferentes velocidades y duración.

El estudio y las pruebas realizadas en los niños de los dos grupos, permitió llegar a la conclusión que el juego de la rayuela, incide en el desarrollo psicomotor de niños de 4 a 5 años de edad.

\section{BIBLIOGRAFÍAS}

Elkonin, D. B., \& Uribes, V. (1980). Psicología del juego (p. 67). Madrid: Pablo del Río.(s.f.).
Blanes García, F. (2005). Braguillas: La lucha contra Franco. Madrid: Entre líneas editores. doi:ISBN: 84-9802-103-0

Cañizares Márquez, J. M., \& Carbonero Celis, C. (2017). El juego motor en tu hijo. España: Wanceulem. doi:978-849993-566-9

Cortázar, J. (1963). Rayuela. París: Editorial sudamericana. Obtenido de https://goo.gl/JhsSrG

Joaquín García, A. M., \& Neciosup De la Cruz , M. L. (2017). Influencia de un Programa de Juegos Tradicionales: yases y rayuela, en el logro de capacidades para operar la Suma y la Resta en las niñas del $3^{\circ}$ grado de la Institución Educativa $n^{\circ} 81007$ Modelo- Trujillo, 2016. Trujillo: Repositorio de la Universidad Nacional de Trujillo. Obtenido de https://goo.gl/dgJiXh

Lapierre, A., Llorca, M., \& Sánchez, J. (2015). Fundamentos de intervención en Psicomotricidad. doi:ISBN: 9788497008112

Le Boulch, J. (1997). El movimiento como forma de expresión. Barcelona: Paidotribo. Recuperado el 2018

Mendieta Toledo, L. B., Vargas Cevallos, T. H., \& Mendieta Toledo, L. R. (2017). Psicomotricidad Infantil (Vol. 1). (CIDE, Ed.) Guayaquil, Guayas, Ecuador: CIDE. doi:ISBN: 978-9942-759-28-3

MinEduc. (12 de agosto de 2017). Educación General Básica - Ministerio de Educación. doi:ISBN: 978-9942-07625-0

CURRÍCULO EDUCACIÓN INICIAL . Quito: Ministerio de Educación del Ecuador, 2014. Obtenido de https:// goo.gl/Zw69Tz

Ortega Ramírez, P., \& Gallegos Samaniego, A. (2016). Los juegos tradicionales se han perdido en la memoria cultural actual de los niños y niñas de la provincia de Santa Elena. YACHANA, 105-114. Obtenido de https://goo.gl/ JzvHYA

Palopoli, M. d. (2006). JUGARTE: La importancia del juego en el aprendizaje de las artes visuales. Buenos $\mathrm{Ai}$ res: Bonum. doi:ISBN: 10:950-507-955-9

Piaget, J., \& Inhelder, B. (2007). Psicología del niño (Décimoséptima ed.). Madrid: Morata. doi:978-84-7112-1032007

Torbert, M. (1982). Juego para el desarrollo motor. México: PAX MÉXICO. doi:ISBN: 968-860-021-0

White, H., Sabarwal , S., \& de Hoop, T. (2014). Síntesis metodológica n. ${ }^{\circ}$ 7: Ensayos controlados aleatorios. Florencia: Centro de Investigaciones Innocenti de UNICEF. Obtenido de https://goo.gl/Ef2e7S 